\title{
Initiatives to increase the prescribing of low cost generics; the case of Scotland in the international context
}

\section{Authors}

Brian Godman1,2, Amanj Baker2, Axel Leporowski3,4, Alec Morton4, Christoph Baumgärtel5, Tomasz Bochenek6, Joseph Fadare7, Alexander Finlayson8, Shazhad Hussain9, Babar Khan10, Marija Kalaba11, Dan Kibuule12, Hye-Young Kwon13, Oyvind Melien14, Renata CRM Nascimento15, Ahmed Salem16, Krijn Schiffers17, Ilse Truter18, Luka Voncina19, Mohamed Azmi Hassali20

\section{Affiliations}

1. Division of Clinical Pharmacology, Karolinska University Hospital Huddinge, Institutet, Stockholm, Sweden

2. Strathclyde Institute of Pharmacy and Biomedical Sciences, Strathclyde University, Glasgow, UK

3. Strathclyde Business School, Strathclyde University, Glasgow, UK

4. Alfred-Weber-Institut für Wirtschaftswissenschaften, RuprechtKarls-Universität Heidelberg, Germany

5. AGES Austrian Medicines and Medical Devices Agency and Austrian Federal Office for Safety in Health Care, Traisengasse, Vienna, Austria.

6. Department of Drug Management, Faculty of Health Sciences, Jagiellonian University Medical College, Krakow, Poland

7. Department of Pharmacology, Ekiti State University, Ado-Ekiti, Nigeria.

8. Nuffield Department of Primary Care Health Sciences, University of Oxford, Oxford, UK

9. National Institute of Health, Islamabad, Pakistan.
10. Department of Pharmacy, University of Lahore, Islamabad Campus, Pakistan

11. The Institute for Medical Care of Mother and Child of Serbia "Dr VukanCupic", RadojaDakića, Belgrade,Serbia

12. School of Pharmacy, Department of Pharmacy Practice and Policy, Faculty of Health Sciences, University of Namibia, Windhoek, Namibia

13. Mokwon University, Division of Biology \& Public Health, Daejeon, South Korea

14. Health Directorate, Ministry of Health, Oslo, Norway. Email: oyvind.melien@helsedir.no

15. Pharmacy College, Federal University of Minas Gerais (UFMG), Belo Horizonte, Minas Gerais, Brazil

16. QuintilesIMS,Brussels, Belgium

17. Ecorys Nederland B.V., Rotterdam, the Netherlands.

18. Drug Utilization Research Unit (DURU), Department of Pharmacy, Nelson Mandela Metropolitan University (NMMU), Port Elizabeth, South Africa.

19. Independent Consultant, Zagreb, Croatia.

20. Discipline of Social and Administrative Pharmacy, School of Pharmaceutical Sciences, Universiti Sains Malaysia, Penang, Malaysia.

\section{Correspondence}

Brian Godman

Email: Brian.Godman@ki.se 


\begin{abstract}
Getting the most out of the pharmaceutical budget is critical across all countries as the financial pressures on healthcare systems intensify. In this paper, we review global practice on encouraging the use of low costs generics versus branded pharmaceuticals, including patented products in the same class where care is not compromised, across countries to guide future practice. Our review ranges widely across European countries as well as other high income countries, including Abu Dhabi, Japan and the USA, and other low and middle income countries. There is a particular focus on Scotland, building on previous publications. We conclude based on multiple publications, including several case studies, that achieving efficiency in pharmaceutical spending is possible in virtually all environments, although there are examples of technologies
\end{abstract}

where generic or therapeutic substitution should not be encouraged. However, there is no magic bullet to achieving full and appropriate use of generics. Countries have to be prepared to use a number of different education, economic, engineering and enforcement methods including prescribing restrictions to achieve success. Similarly, different approaches to achieve low prices for good quality generics given the considerable price differences that currently exist. The combination of low prices and increased use of generics will help achieve or attain universal healthcare, benefiting all key stakeholder groups. We conclude with a call for greater cross-country learning in pursuit of what should be a common goal for all health systems.

Keywords: Co-payments, compulsory substitution, generics, prescribing restrictions, prices, reforms, Scotland 
Initiatives to increase the prescribing of low cost generics; the case of Scotland in the international context

\section{Introduction}

Increasing the prescribing and dispensing of generics versus originators, or patented products in a class where care is not compromised, is essential to enhance access to medicines as well as, maintain or attain comprehensive healthcare given ever increasing resource pressures (1-3). We are now seeing even high income countries struggling to fund new valued premium priced medicines $(2,4)$. As the population ages, this phenomenon will worsen unless adequately addressed $(1,5)$. Increasing the prescribing and dispensing of generics is particularly important in lower and middle income countries (LMICs) where up to $70 \%$ of total healthcare costs are spent on medicines; a significant proportion of which can be out-of-pocket, and where considerable savings can be made (6-9). Lowering the prices of generics among Central and Eastern European countries can also be beneficial, especially where copayments are high and a barrier to appropriate care(10).

The availability of generic antiretroviral (ARVs) medicines are of particular importance in LMICs, especially in subSaharan countries, where up to $69 \%$ of the 34 million worldwide cases of HIV currently reside and where $41 \%$ of the population currently live on less than US\$1.25 per day (11-15). Studies have shown that the availability of generic ARVs not only decreases the costs of treatment, but has a positive impact on treatment compliance, leading to decreased morbidity, mortality and rates of transmission (16-19). The cost of highly active antiretroviral therapy (HAART) decreased 20-fold after generic HAART in India, with a 5 fold reduction in mortality (20). Increased access to generic antibiotics has also helped combat infection in many LMICs (21); however, increasing antibiotic availability has increased resistance rates (22).
The increasing availability of low cost generics for patients with cancer, including novel cancer medicines such as the tyrosine kinase inhibitors, will also increase the number of patients that can be effectively treated $(23,24)$. In addition, help address health authority concerns with ever increasing prices for new cancer medicines, which are now threatening access for patients and the sustainability of healthcare systems (23, 25-27). However, the availability of sub-standard generic cancer medicines is a concern to physicians, patients and health service managers, which needs to be addressed (24).

Low cost generics can also help increase adherence to medicines, with adherence critical for the effective treatment of chronic diseases including HIV as well as noncommunicable diseases (NCDs) such as diabetes, hypercholesterolaemia and arterial hypertension (28-34). Adherence is negatively affected not only by the complexity of prescribed drug regimens, their safety or tolerability, but also by issues of co-payments in a number of countries as well as health care systems (35-46).

Recent publications have demonstrated similar effectiveness between generics and originators across a range of molecules and disease areas (46-60), and addressed concerns even where different salts have been used for generics, e.g. generic clopidogrel (61). However, concerns still exist about the quality of generics and their effectiveness, especially in some classes and countries, as well as issues with substitution impacting on potential savings $(3,8,24,62$ 77). This includes concerns with generic lopinavir/ ritonavir in recent years, which is the cornerstone of second-line ARVs (11), resulting in suggestions for dynamic ongoing surveillance. Concerns with the quality of generics has also resulted in suggestions for better monitoring of the 
Initiatives to increase the prescribing of low cost generics; the case of Scotland in the international context

ingredients as seen recently in Pakistan (78). Key stakeholder concerns with substitution with a limited number of molecules has resulted in countries, including Sweden and the United Kingdom (UK), issuing guidance on which molecules should not be substituted (Box 1 Section 3.2.2), with the Royal Dutch Pharmacists Association issuing similar guidance to their members (79-82). There is now less concern with substituting generic immunosuppressive medicines than originally thought $(83,84)$. However, care is needed regarding potential strategies and their outcome with a recent systematic review on generic substitution demonstrating that that while health outcomes appear similar following substitution, the full extent of potential savings are not guaranteed (85).

There have been concerns among health authorities if pharmaceutical companies heavily discount prices of their branded medicines in hospitals with the expectation that patients will be discharged on more expensive medicines, greatly increasing costs in ambulatory care (86-88). In addition, if companies launch patented follow-on products just before patent expiry of the initial molecule to limit revenue loss, referred to as ,evergreening strategies ${ }^{\text {ee }}$ (89). There are also concerns if pharmaceutical companies pay generic companies to delay launching their generics, as well as instigating other tactics such as product hopping, to try and reduce generic use (41, 65, 90-93). These strategies are all potentially counter-productive especially if pharmaceutical companies wish public monies to fund their new more expensive medicines with increasing pressure on resources $(4,94)$.

Some studies suggest that there can be confusion among patients if they are dispensed different branded generics with different names without explanation, leading potentially to under- and over- dosing (95), although others did not find such problems (96). In any event, concerns with generics need to be addressed to maximise potential savings from their availability.

There have been varying measures across countries to lower the price of generics (2, $75,97-102)$ as well as enhance their use versus originators $(1,2,9,99,103-107)$. There have also been multiple initiatives across countries to enhance the use of generics in a class versus patented products to conserve resources where this does not compromise care. Classes include the proton pump inhibitors (PPIs), renin-angiotensin inhibitors and the statins $(10,102,108-111)$. There have also been initiatives among health authorities to influence the prescribing of generic versus patented antidepressants, although recognising that there can be inter-patient variation $(101,112$, 113).

Consequently, the aim of this paper is to review ongoing measures among health authorities across countries to enhance the prescribing of low cost generics, whether successful or not, and the implications to guide future activities. We will also perform a deeper analysis outlining recent changes in prescribing behaviour in Scotland and the outcomes to anchor key discussion points.

\section{Methods}

\subsection{General measures regarding pricing and utilisation of generics}

This is principally a descriptive review of regulations, meta analyses and other relevant papers known to the co-authors rather than an extensive literature search of peer-reviewed publications regarding attitudes and policies towards generics as these have already been published $(1,9,67$, 77, 85, 94, 97-99, 103, 104, 106, 107, 114119). In addition, a history of time lines 
Initiatives to increase the prescribing of low cost generics; the case of Scotland in the international context

surrounding the regulations for medicines including generics has also recently been published (71).

Demand-side measures discussed in this paper will again be collated under the 4Es, namely education, engineering, economics and enforcement (120). These include (81, $88,97,100,111,112,120-131)$ :

- Education - activities range from recommended medicines such as the „Wise Liste in Stockholm, Sweden, to printed guidelines as well as more intensive strategies including academic detailing and benchmarking physician prescribing habits.

- Economics - initiatives falling under this category include financial incentives for physicians, patients or pharmacists. These include additional co-payments if patients want a more expensive medicine than the referenced price generic.

- Engineering - this typically refers to managerial or organisational interventions such as prescribing targets and switching initiatives as seen with losartan versus other angiotensin receptor blockers (ARBs) once generics became available in England and Sweden.

- Enforcement - includes regulations by law such as compulsory generic substitution or compulsory international non-proprietary name (INN) prescribing in Abu Dhabi, Lithuania, South Africa and Sweden as well as prescribing restrictions for angiotensin receptor blockers (ARBs) in Austria, Belgium, the Republic of Srpska (Bosnia and Herzegovina) andSweden.

We will first review strategies to achieve low prices for generics before reviewing different strategies to influence their prescribing versus originators and patented products in a class.

\subsection{Scotland}

We will also include an update on the influence of multiple measures in Scotland to enhance the prescribing of low cost generics versus originators and patented products in a class to provide a focus in the discussion. This builds on previous publications $(101,108,132)$.

Data from the National Health Services Scotland Warehouse has again been used to analyse trends in the utilisation and expenditure of key products and classes in Scotland. This again includes the PPIs, selective serotonin reuptake inhibitors (SSRIs), and statins. Items dispensed, which is typically 28 days, has been used as the utilisation metric in this update instead of defined daily doses (DDDs), which is the internationally recognised standard for drug utilisation studies $(133,134)$. This is because, items dispensed is the usual metric used in the United Kingdom when evaluatingphysician prescribing(129).

\section{Results}

\subsection{Prices ofgenerics}

\subsubsection{Prices of generics-Europe}

Prices of generics can vary 36 fold or more across countries depending on the molecule and the price setting mechanisms for generics in that country $(2,97,115)$. European countries also have different approaches to the pricing of generics (10, 97, 108, 116). However, they can be typically categorised under three headings (97, 116, 135) including:

- Price regulated systems (prescriptive pricing) - where there are established rules for the pricing of generics, e.g. Croatia, France, Norway and Poland (136-139)

- Free pricing - where manufacturers are (relatively) free to set the prices of 


\section{Initiatives to increase the prescribing of low cost generics; the case of Scotland in the international context}

generics, e.g. Germany, Netherlands, Sweden and the UK. However, there are typically programmes in place to lower prices which include compulsory generic substitution in Sweden linked to monthly tendering, 3-monthly preference pricing policies in the Netherlands linked to tendering and 3monthly review of prices in the UK $(81$, $102,119,132,140)$

- Mixed approach - where a combination of approaches are used, e.g. Austria $(141,142)$

The various approaches can result in substantial differences in the prices of generics among different European countries. In European countries with aggressive measures to lower generic prices, generic prices can be as low as $2 \%$ to $4 \%$ of the pre-patent loss prices, e.g. Netherlands, Sweden and the UK for generic simvastatin and the Netherlands for generic omeprazole $(81,102,132)$.

The preference pricing policy was instigated in the Netherlands in 2008 whereby only the cheapest generics would be reimbursed, with patients covering the costs for a nonpreferred drug $(94,102)$. Tenders were subsequently conducted for high volume generics resulting in further price reductions of between $76 \%$ to $93 \%$ for the 10 largest generics by volume (94). Dylst et al calculated that without aggressive pricing policies to lower the price of generic omeprazole, and increase its utilisation versus the originator, the Dutch government would have spent an additional $€ 3.723$ billion on omeprazole between 2002 and 2013, assuming similar utilisation rates and prices remained at pre-patent loss prices (41). Overall, it is estimated that the introduction of these policies in the Netherlands reduced pharmaceutical expenditure by $€ 0.75$ - $€ 0.90$ bn per year over the past five years (2).
Prices for high-volume generics fell to 4 to $13 \%$ of originator pre-patent loss prices in Sweden by 2009 , helped by compulsory substitution introduced in 2002 and a comprehensive technical support system enabling pharmacies to continually stock the cheapest product, with prices reviewed at least twice a month (81). Overall savings from generic substitution were estimated at $€ 700$ million (>6.97 billion SEK) from 2002 to the end of $2005(81,94)$. Savings are greater following the introduction of the monthly tendering process at 8 billion SEK/year from 2011 onwards (94).

The situation regarding generic pricing is different in Belgium. The prices of generic drugs have to be lowered at least to the reference price to be reimbursed in Belgium, which was a $16 \%$ reduction versus pre-patent loss prices until 2002, 20\% until 2003, 26\% until 2005, and currently $31 \%$, with the potential for further lowering after that $(109,131)$. The only major exception was the statins where as a result of a public tendering system in January 2008, prices for simvastatin were further lowered by on average $40 \%$ (109). As a result, generic losartan in 2011 was only $46 \%$ below prepatent loss prices and generic omeprazole in 2009 was only $70 \%$ below pre-patent loss prices, whilst generic simvastatin was $85 \%$ below pre-patent loss prices $(109,131)$. This compares with the price of generic losartan in Sweden in 2011 at 90\% below pre-patent loss prices (expenditure/ DDD) (128), with a similar low price in Scotland (Table 1).

Prices of generics in Poland are regulated through price negotiations and reimbursement decisions issued by the Minister of Health (143). The price of the first generic has to be at least $25 \%$ lower than the solitary product (usually the originator) which is already included in the reimbursement list. Prices of all other generic equivalents, which subsequently apply for reimbursement, cannot be higher 
Initiatives to increase the prescribing of low cost generics; the case of Scotland in the international context

than the reference price in a given reference group (usually one of the cheapest products but not always). These policies are in place together with the typical practice of granting reimbursement status to a wide spectrum of applying equivalent products (144). In many cases, this results in groups containing a number of generics and their originator, where prices do not appear to be the major factor in the prescribing decision. When coupled with insufficient educational activities, and a lack of promotion of generics, this can result in a high market share of expensive branded generics or originators to the detriment of cheaper generics.

The size of the European country does not appear to be a barrier to obtaining low prices for generics as seen in Lithuania and the Republic of Srpska $(122,125)$ despite comments to the contrary (145). Overall, prices of generics in Europe typically fall further from pre-patent loss prices in high versus low volume generic markets (117). In European countries with high volume generic markets, Dylst et al showed prices among 35 active substances that had lost their patents dropped by $43.2 \%$ by the end of the study period; this compares with only $21.6 \%$ in low volume generic markets (117).

The differences in the approaches to the pricing of generics among European countries can also lead to substantial differences between originator and generic prices (98), with for instance Greece, Ireland and Spain displaying lower price differences that Denmark, Finland and Sweden (98). For example, sumatriptan saw a price decrease in Greece of $5.8 \%$ when compared to the originator, while in Denmark the variation was $95 \%$.

\subsubsection{Prices of generics-Other countries}

There are concerns with high prices of generics in a number of non-European countries including Australia, African countries such as Nigeria, and Malaysia (74, 146-149). Prices in Malaysia are not helped by the lack of any established pricing policy compared with European countries (Section 3.1.1) (74). Prices of generics in the private healthcare sector in South Africa were also high with no formal pricing system, e.g. generic PPIs in 2010 were only $32 \%$ to $64 \%$ lower than originator prices with generic statins only $33 \%$ to $51 \%$ below originator prices in $2011(100,150)$.

Recently, „Novartis Access" was launched in Kenya, which is a portfolio of 15 principally oral medicines for patients with NCDs, part of EssentialMedicine Lists, at a cost of US\$1/ treatment/ month (151). This programme will be extended to other countries as it is envisaged to be commercially sustainable over the long term (151). Such initiatives should help to substantially lower generic prices in Africa and other LMICs enhancing medicine access.

Care is needed though when introducing new pricing policies for generics as seen in South Korea. The Korean government implemented a new pricing policy in 2012 in order to try and make the generic market more competitive through setting the same maximum reimbursement price between originators and generics (75). It was envisaged this would increase competition among generic manufacturers to lower their prices. However given the concerns that still exist regarding generics among physicians in Korea, the opposite was achieved. The price dispersion between different generics significantly decreased, and originator-togeneric utilization significantly increased (75).

\subsubsection{Prices of generics - Scotland}

The combination of high voluntary INN prescribing (see section 3.2.2), coupled with 
Initiatives to increase the prescribing of low cost generics; the case of Scotland in the international context

measures to lower the prices of generics every 3 months through increased transparency (see Bennie et al 2012 and
Godman et al 2013 for details $(101,132))$, has resulted in typically low prices for a range of generics in Scotland (Table 1).

Table 1 - Prices of generics as a percentage of pre-patent loss originator prices (amended from $\underline{(101,132,152,153))}$

\begin{tabular}{|c|c|}
\hline & $\begin{array}{l}\% \text { of prepatent loss prices in the designated } \\
\text { year }\end{array}$ \\
\hline \multicolumn{2}{|l|}{ Antipsychotics } \\
\hline Risperidone & $16 \%$ in 2010 \\
\hline \multicolumn{2}{|l|}{ ARBs } \\
\hline Losartan & $12 \%$ in 2012 \\
\hline \multicolumn{2}{|l|}{ PPIs } \\
\hline Lansoprazole & $8 \%$ in 2015 \\
\hline Omeprazole & $9 \%$ in $2010,7 \%$ in 2015 \\
\hline Pantoprazole & $10 \%$ in 2015 \\
\hline \multicolumn{2}{|l|}{ SSRIS } \\
\hline Citalopram & $8 \%$ in 2015 \\
\hline Paroxetine & $16 \%$ in 2015 \\
\hline \multicolumn{2}{|l|}{ Statins } \\
\hline Atorvastatin & $8 \%$ in 2015 \\
\hline Simvastatin & $3 \%$ in $2010,4 \%$ in 2015 \\
\hline
\end{tabular}

NB: ARB = angiotensin receptor blocker, PPI = proton pump inhibitor, SSRI = selective serotonin reuptake inhibitor

\subsection{Enhancing the utilisation of generics versus originators}

\subsubsection{Europe}

Health authorities across Europe use a variety of measures to encourage the prescribing of generics versus originators (brand name products), some of which are described in Table 2. Overall, multiple initiatives typically have a greater influence on future prescribing habits than more limited measures, in accordance with previous publications $(10,108,154,155)$. 
Initiatives to increase the prescribing of low cost generics; the case of Scotland in the international context

Table 2 - Examples of measures used by health authorities across Europe to encourage the prescribing and dispensing of generics vs. originators (brand name molecules)

\begin{tabular}{|c|c|}
\hline Initiatives and countries & Description \\
\hline $\begin{array}{l}\text { Education - encouraging } \\
\text { high voluntary international } \\
\text { non-proprietary name } \\
\text { (INN) prescribing - } \\
\text { education - UK }(9,80,101 \text {, } \\
132,156,157)\end{array}$ & $\begin{array}{l}\text { - Multiple educational activities among physicians in the UK } \\
\text { during training and post qualification, including decision } \\
\text { support software and monitoring, has resulted in highINN } \\
\text { prescribing } \\
\text { - INN prescribing averages over } 84 \% \text { across all products, } \\
\text { rising to over } 98 \% \text { for most generics (Table } 3 \text { ) } \\
\text { - There are a recognised limited number of medicines where } \\
\text { INN prescribing is not encouraged (Box 1) }\end{array}$ \\
\hline $\begin{array}{l}\text { Education and economics - } \\
\text { Austria }\end{array}$ & $\begin{array}{l}\text { - Several initiatives nationally to educate key stakeholders } \\
\text { regarding generics, including dispelling myths such as the } \\
\text { myths that existed with generic clopidogrel }(61,158) \\
\text { - The Sickness Funds in Austria also use a variety of } \\
\text { approaches to enhance the prescribing of generics among } \\
\text { physicians. These include training, monthly newsletters on } \\
\text { changes in the reimbursement list, information events, } \\
\text { personal visits to discuss prescribing habits, analysis of } \\
\text { prescriptions and feedback/ benchmarking and software } \\
\text { systems(105) } \\
\text { - Physicians in Austria receive financial incentives for } \\
\text { increased prescribing of generics versus originators (105, } \\
\text { 141) } \\
\text { Despite these initiatives, generic losartan accounted for } \\
\text { only } 46 \% \text { of total losartan on a DDD basis in 2011 (142) }\end{array}$ \\
\hline $\begin{array}{l}\text { Education, economics and } \\
\text { engineering - France }(94, \\
103,116,136)\end{array}$ & $\begin{array}{l}\text { - The French authorities regularly publish and update the list } \\
\text { of available generics } \\
\text { - Health Insurance Funds provide regular feedback to } \\
\text { physicians on their generic prescribing rates } \\
\text { - This combined with quality targets for physicians, } \\
\text { substitution targets and incentives for pharmacists, } \\
\text { financial incentives for patients as well as a prescriptive } \\
\text { pricing policy for generics, led to estimated annual savings } \\
\text { of } € 1 \text { bn in } 2007, € 0.905 \text { bn in } 2008 \text { and } € 1.01 \text { bn in } 2009 \\
\text { The financial incentives for pharmacists are for reaching } \\
\text { national/regionalagreed substitutiontargets }\end{array}$ \\
\hline $\begin{array}{lcr}\text { Economics } & - & \text { financial } \\
\text { incentives for } & \text { patients } \\
\text { (various countries) } & \end{array}$ & $\begin{array}{l}\text { - There is internal reference pricing }(97,99) \text { in the majority } \\
\text { of European countries } \\
\text { - Under this system, patients typically pay the additional } \\
\text { cost themselves for a more expensive medicine than the } \\
\text { referenced priced generic medicine to encourage the } \\
\text { prescribing of cheapergenerics } \\
\text { - This includes the Netherlands with its preference pricing } \\
\text { policy (see section 3.1.1) }\end{array}$ \\
\hline Economics - Germany & - Physician prescribing costs regularly benchmarked, with \\
\hline
\end{tabular}


Initiatives to increase the prescribing of low cost generics; the case of Scotland in the international context

\begin{tabular}{|c|c|}
\hline$(116)$ & $\begin{array}{l}\text { potential financial sanctions for continued over budget } \\
\text { costs } \\
\text { - Abolishing patient co-payments if reimbursed prices of the } \\
\text { generic is at least } 30 \% \text { below current reference prices } \\
\text { - Potentially reducing or abolishing co-payments if } \\
\text { physicians prescribe drugs where the Sickness Funds have } \\
\text { successfully negotiated contracts. The rebates, included } \\
\text { those for patented drugs, resulted in estimated savings of } \\
€ 1.3 \text { bn in } 2010 \\
\text { Despite these measures, reimbursed prices for generics can } \\
\text { be appreciably higher in Germany than e.g. Netherlands or } \\
\text { the UK }\end{array}$ \\
\hline $\begin{array}{l}\text { Enforcement - Compulsory } \\
\text { INN prescribing } \\
\text { Lithuania }(116,125)\end{array}$ & $\begin{array}{l}\text { - There is compulsory INN prescribing in Lithuania unless } \\
\text { prior approval from the Hospital or Polyclinic Therapeutic } \\
\text { Committee } \\
\text { - Pharmacists in Lithuania are obliged to stock the cheapest } \\
\text { generics with financial penalties if they do not comply } \\
\text { - Overall, INN prescribing is mandatory in at least } 5 \\
\text { Europeancountries(99) }\end{array}$ \\
\hline $\begin{array}{l}\text { Enforcement - Compulsory } \\
\text { substitution - Sweden ( } 81 \text {, } \\
112,128,159-162)\end{array}$ & $\begin{array}{l}\text { - There has been mandatory generic substitution in } \\
\text { pharmacies in Sweden from } 2002 \text { onwards apart from a } \\
\text { minority of situations (similar to the UK - Box 1), with } \\
\text { patients covering the additional costs themselves for a } \\
\text { higher costmedicine including the originator } \\
\text { - Key stakeholder groups were typically supportive of this, } \\
\text { although concerns if patients are not fully informed that } \\
\text { their medicine could have a different name } \\
\text { - As a result, } 96 \% \text { of risperidone by volume was generic, } \\
97.4 \% \text { of total losartan was generic and } 99.6 \% \text { of } \\
\text { venlafaxine was genericin } 2011 \\
\text { Overall, generic substitution is mandatory in at least } 6 \\
\text { Europeancountries(99) }\end{array}$ \\
\hline $\begin{array}{l}\text { Education, economics and } \\
\text { enforcement }- \text { Poland } \\
(143)\end{array}$ & $\begin{array}{l}\text { - Price ceiling established by the reference product in a } \\
\text { given reference group (Section } 3.1 .1 \text { ) } \\
\text { - The retail margin at the pharmacy level is currently based } \\
\text { on the reference price instead of a given productes retail } \\
\text { price } \\
\text { - This can result in pharmacistes price indifference when } \\
\text { filling a prescription for reimbursed products which have } \\
\text { generic equivalents } \\
\text { - This is despite compulsory informing patients (pharmacist } \\
\text { obligation) on the possibility of receiving a cheaper } \\
\text { reimbursed generic equivalent, whose price does not } \\
\text { exceed the reimbursement limit. As a result, potentially } \\
\text { reducing co-payments }\end{array}$ \\
\hline
\end{tabular}


Initiatives to increase the prescribing of low cost generics; the case of Scotland in the international context

\subsubsection{UKincluding Scotland}

Alongside high INN prescribing rates inthe

UK (Table 3), there are a small number of products and classes where substitution is not encouraged (Box 1).

Box 1 - Examples where concerns with INN prescribing in the UK based on recommendations in the British National Formulary (BNF), the Council of the Royal Pharmaceutical Society and the Medicines and Healthcare Products Regulatory Agency (adapted from $(79,80,84,163)$ )

- Amphotericin intravenous - prescribe by brand name as doses depend on the formulation

- Asthma treatments:

○ Theophylline modified release preparations - typically not seen as interchangeable due to concerns with the clinical implications of switchingbetweeninequivalentpreparations

- Beclometasone dipropionate CFC-free inhalers - care where administration approaches differ with differentinstructions

- Calcium antagonists - care with modified release preparations as typically not seen as interchangeable

- Drugs for rejection - relatively small number of eligible studies with hard to compare methods make recommendations difficult. However generic immunosuppressants such as generic cyclosporine have been on the market in Europe for more than 10 years with no identified serious safety signals among the many doses prescribed and dispensed

- Epilepsy - in view of the different publications, the Medicine Agency recently issued the following advice:

○ Category 1 - phenytoin, carbamazepine, phenobarbital, and primidone Physicians are advised to ensure that patients are maintained on a specific manufacturer"es product

- Category 2 - valproate, lamotrigine, perampanel, retigabine, rufinamide, clobazam, clonazepam, oxcarbazepine, eslicarbazepine, zonisamide, and topiramate - the need for continued supply of a particular product should be based on clinical judgement and consultation with patients taking into account considerations such as seizure frequency

○ Category 3 - levetiracetam, lacosamide, tiagabine, gabapentin, pregabalin, ethosuximide, and vigabatrin - usually unnecessary to ensure that patients are maintained on a specific manufacturer"es product

- Lithium - concerns with differences in bioavailability between different formulations suggesting care when considering any substitution.

- Morphine sulphate slow release tablets - doses prescribed should be reviewed if the brand is changed as there may be different release patterns between the different formulations - similar situation regarding fentanyl transdermal formulations 
Initiatives to increase the prescribing of low cost generics; the case of Scotland in the international context

Typically rates of generic prescribing across high volume classes including angiotensin inhibitors and statins were $98 \%$ antidepressants, antipsychotics, PPIs, reninor more in recent years (Table 3).

Table 3 - Percentage of generics as a percent of total molecules dispensed (DDDs or items dispensed) in Scotland (adapted from (101))

\begin{tabular}{|l|c|}
\hline Class & $\begin{array}{c}\text { \% of generic utilisation in defined daily doses } \\
\text { (before 2015) and items dispensed (2015) }\end{array}$ \\
\hline Atypical antipsychotics & 98\% in 2009 \\
\hline Risperidone & 98\% in 2010, 99.1\% in 2015 \\
\hline PPIs & $98.8 \%$ in 2015 \\
\hline Omeprazole & $99.9 \%$ in 2015 \\
\hline Lanzoprazole & \\
\hline Pantoprazole & $98 \%$ in 2010, 99.1\% 2015 \\
\hline Statins & $99.7 \%$ in 2015 \\
\hline Simvastatin & \\
\hline Atorvastatin & \\
\hline Renin-angiotensin inhibitors & $99 \%$ in 2007 \\
\hline ACEls & $98 \%$ in 2007 \\
\hline Enalapril & \\
\hline Lisinopril & $99 \%$ in 2011 \\
\hline ARBs & \\
\hline Losartan & $99 \%$ in 2007, 99.9\% in 2015 \\
\hline SSRIs & $98 \%$ in 2007, 99.6\% in 2015 \\
\hline Citalopram & $98 \%$ in 2007, 99.7\% in 2015 \\
\hline Fluoxetine & \\
\hline Sertraline & \\
\hline NB: ACEI angiotensin & \\
\hline
\end{tabular}

NB: $\mathbf{A C E I}=$ angiotensin converting enzyme inhibitor, $\mathbf{A R B}=$ angiotensin receptor blocker, $\mathbf{P P I}=$ proton pump inhibitor, $\mathbf{S S R I}=$ selective serotonin reuptake inhibitor

\subsubsection{Lower and Middle Income Countries (LMICs)}

The WHO proposes that optimally all medicines $(100 \%)$ should be prescribed by their generic (INN) name (164). However, there is room for considerable improvement with a recent meta-analysis by Ofori-Asenso et al showing that the percentage of medicines prescribed by generic name across Africa was only $68.0 \%$ (IQR 55.480.3) (165).
This is important with Cameron et al demonstrating that substantial savings could be made among 17 LMICs from switching from originator brands to the lowest-priced generic equivalent (7). As an example in Thailand, implementation of generic substitution policies with the lowest priced generic would yield average annual potential savings of US\$ 3.997 million for seven medicines alone $(7,9)$. Suggested strategies to enhance generic uptake, that could be incorporated into national medicine policies, included substitution by pharmacists as well as increasing 
Initiatives to increase the prescribing of low cost generics; the case of Scotland in the international context

confidence in generics among key stakeholder groups (7).

In Mexico, generics and interchangeable generics are currently seen as different products. Here, there are not only patented medicines and generics, but also "similar" and "interchangeable" medicines. This can confuse patients and affects how they perceive the safety and efficacy of generics overall since similar products are marketed as bio-equivalent, when they are not. Consequently, there can be mistrust in generics by patients and physicians (166). This is despite the fact that it is mandatory for physicians to prescribe by generic name; however, they can prescribe a brand name if the recommendation is placed between parenthesis. In this way, patients have the right tochoose.

A generic drug policy were established in Brazil in 1999, which includes a generics preference policy in public purchases, mandatory generic substitution in public pharmacies, availability of generic drugs lists published by the regulatory agency (ANVISA), and educational activities among health professionals. Generics were typically introduced on average $40 \%$ lower than the price of the patented medicine, with this difference increasing to $68 \%$ lower in recent years. Brazil is a "pharmemerging" country with domestic companies marketing low cost generics. Despite these various initiatives though, generics only accounted for $27.3 \%$ of Brazilian pharmaceutical sales in 2013. The main barrier being the low confidence that physicians have in the quality of generics (167-169).

In their recent comprehensive review, Hassali et al also found physicians from LMICs tend to have mixed views regarding generic medicines. The authors believed this may be due to differences in the health care systems and medicine policies, including how medicines are funded, as well as differences in income levels. In addition, the extent of educational initiatives among key stakeholder groups as well as available drug information sources (67). Concerns with therapeutic failure among physicians in Nigeria, especially among locally produced generics, also potentially discourages their use (63). There are also concerns between the perceived and actual quality of generics in South Africa, again potentially affecting their use(3).

Having said this, there have been only a limited number of policy evaluations to date to determine which of the potential policies and measures LMICs could introduce to increase the utilisation of generic medicines in their countries (106). Ensuring a functioning medicines regulation system for marketing authorisation, creating a robust market as well as aligning incentives for all key stakeholder groups appear necessary prerequisites for increasing the utilisation of generics in LMICs (106).

Truter in her recent study found increasing use of generic meprobamate analgesic combination in a retrospective study of a medical health insurance claims database. There is compulsory generic substitution in South Africa unless otherwise specified by the physician or the patient prefers to pay for the more expensive originator. This is unlikely in this case in view of the price difference $(170,171)$. Her study found that the originator constituted only $3.7 \%$ of the analgesics prescribed (average cost was R30.42) compared to $70.6 \%$ for the most popular branded generic, with a cost of R11.65 (170, 171).

However, there has been low use of generics versus originators among hospitals in China, where most medicines are dispensed, when compared to a number of European countries (172-174), e.g. generic statins accounted for only $9 \%$ to $10 \%$ of total statins in recent years in hospitals in China 
Initiatives to increase the prescribing of low cost generics; the case of Scotland in the international context

(175). The low use of generics is exacerbated by the need for hospitals to make money from drug procurement for their sustainability and physicians to supplement their income, with this incentive system also stimulating overuse of injections (174, 176-178). Having said this, Li et al recently demonstrated that patients could be successfully switched from imported originator anti-depressants to locally produced generics following education and psychological support without affecting subsequent care (179).

In recent publications from Malaysia, Chua et al demonstrated that private GPs in Malaysia have largely accepted generic medicines. However, they still have concerns regarding their reliability and quality necessitating further education and reassurance (72). Kumar et al also recently demonstrated that the majority of the physicians among private medical centres in Malaysia had negative perceptions about the safety and efficacy of generic medicines, impacting on their use (74). Similar approaches are needed to address this including reassurance of the quality of generics as well as physician education (74). There are also still concerns with generic substitution in Malaysia, enhanced by fears regarding the efficacy and safety of generics (74). This resulted in Hassali et al developing a list of requirements that should be met to enhance successful generic substitution (Box 2).

Box 2 - Potential requirements to successfully implement a generic substitution policy (adapted from (118)).

- Pharmacists and patients should communicate with each other to understand the safety and suitability of the alternate brands to improve patient acceptability of generics

- A formulary of interchangeable medicines must be developed as well as medicines that should not be substituted (Box 1)

- Requirements for marketing authorization must include (i) a license for manufacturing and marketing; (ii) the factory must have a license or accreditation for manufacturing the generic, which must comply with the country's GMP. As a result, strict quality standards forgenerics

- The length of the supply chain should be reduced to avoid unnecessary distribution costs to ensure affordable prices

- Education is important with the government and physicians responsible for disseminating appropriate information about generics. Pharmacists and physicians should have positive perceptions toward generic substitution

- Labelling by INN to avoid patient confusion - as seen in the UK

- Pharmacists should have a system where they can access relevant information about generic medicines before dispensing them as well as have the authority to change to a generic unless the patient demands the originator and/or the physician indicates do not substitute

\subsubsection{Other countries}

In 2012, Japan modified its prescription format to allow generic substitution for individual medicines to encourage greater generic prescribing, although physicians can also indicate ,no substitution ${ }^{\text {ee }}$ if concerns (24). Generic substitution is encouraged as it is estimated successful implementation would result in estimated savings of 
Japanese Yen (JPY) 1.3 trillion per year. This is coupled with financial incentives for physicians and pharmacists to enhance their generic prescribing and dispensing (9). However despite these moves, the utilisation of generics remains low in Japan. This is because there are still negative perceptions towards generics, pharmacists are reluctant to recommend them, and there is currently limited cost differences between generics and originators in practice (9).

However, care is needed when introducing policies such as compulsory INN prescribing as recently seen in Abu Dhabi (130). Compulsory INN prescribing was not backed up by multiple policies among physicians to enhance the preferential prescribing of multiple-sourced medicines in the class. In addition, pharmacists could still dispense different brands of the same product and be reimbursed in full. As a result, there was increased utilisation of patent protected products and the envisaged savings were not attained (130).

\subsubsection{Addressing concerns with the efficacy and safety of generics}

As seen, education and effective regulatory systems are key to addressing concerns with generics, where these exist, given the extensive number of publications that have demonstrated similar effectiveness between generics and originators for generics meeting agreed quality standards $(3,24,67$, 106).

Concerns with the complexity, production, and distribution of generics has highlighted the need for convergence of regulations. This has resulted in the instigation of the „International Generic Drug Regulators Programmee, which comprises regulatory bodies from several countries as well as the WHO (24).
To help address concerns in the US, the FDA in 2014 issued 18 warning letters to generic manufacturers oversees, and in 2015 undertook multiple inspections in for instance in India as well as increasing its office staff there (24). The FDA has also banned generics manufactured at several facilities in India until improvements, as well as fined manufacturers for selling adulterated generics. The EMA has also recommended countries to withdraw a large number of generic medicines whose pivotal trials were performed fraudulently with GCP variations by one Indian contract research organisation, leading to concerns with data quality (24). Such initiatives will continue through steadily enlarging authorities ${ }^{\text {ee }}$ inspection activities. In addition, the Central Drugs Standard Control Organization (CDSCO) in India will soon start making surprise inspections among manufacturing sites to improve the quality (24).

Khan et al recently suggested ways to improve the quality of generics in Pakistan in view of concerns with the quality of the active ingredient (78). Concerns with their quality resulted in some manufacturers increasing the quantity of the active ingredient in the manufacturing process, which is not in the best interest of any key stakeholder group as this could lead to overdosing.

It should be borne in mind though that efficacy and safety concerns have also arisen with different batches of patented products (71).

\subsection{Increasing the prescribing of generics (multiple sourced products) vs patented products in a class}

There are also a variety of measures that health authorities have used to encourage physicians to increase their prescribing of generics versus patented products in a class 
Initiatives to increase the prescribing of low cost generics; the case of Scotland in the international context

to save resources without compromising care $(53,55,59,180-182)$. These measures are more prevalent in countries with high volumes of generics (117) and involve (i) educational initiatives among physicians including guidelines, academic detailing and benchmarking physician prescribing habits; (ii) incentive schemes (financial incentives); (iii) encouraging switching as well as prescribing targets (engineering) and (iv) prescribing restrictions (enforcement) (59, $77,103,108,110,111,128,129,136,138$, $158,183,184)$. Classes include the proton pump inhibitors (PPIs), renin-angiotensin inhibitors and the statins $(1,59,110,111$, $124,185,186)$. In addition, antidepressants in certain countries $(101,112)$. However, there are classes where health authorities are not active with influencing prescribing patterns. These include the antipsychotics (Section 3.3.4). Again, multiple initiatives typically have a greater influence on future prescribing habits than a more limited number of measures $(10,108,154,155)$.

In the US in 2005, it was estimated that US\$20billion could be saved annually in 8 medicine classes among the commercially insured patients if there was therapeutic interchange to guideline adherent medicines (46). More recently, it was estimated by Gellad et al that Medicare could save US\$1.4billion alone each year for patients with diabetes if prescribing mirrored the VA (Veterans Administration) system combining generic substitution and therapeuticinterchange(187).

\subsubsection{PPIs across Europe excluding Scotland}

Multiple demand-side initiatives were instigated in a number of European countries to increase the prescribing of generic versus patented PPIs, combined with measures to lower generic prices (Section 3.1), to enhance prescribing efficiency as no perceived difference in effectiveness between the different PPIs (10, $46,108)$. Typically, countries that instigated multiple policies limited the prescribing of patented PPIs versus those countries with more limited demand-side measures $(1,10$, 108). This is illustrated by:

- Sweden versus Ireland $(10,108)$

○ Multiple demand side measures, including education, economics, and engineering, appreciably increased the prescribing of omeprazole in Sweden once generics became available and limited the utilisation of esomeprazole to less than $20 \%$ on a DDD basis by the end of 2007

- There was limited demand-side measures in Ireland. As a result of commercial activities, utilisation of omeprazole decreased following generic avaialbility with esomeprazole increasing, with the utilisation of both approximately $30 \%$ of total PPI utilisation in 2007

- These activities, combined with the measures to lower the prices of generics in Sweden (Section 3.1), resulted in reimbursed expenditure for the PPIs in Sweden decreasing by $49 \%$ in 2007 vs. 2001 despite utilisation increasing by $53 \%$. In Ireland (GMS population - greater comorbidity than the normal population), utilisation increased by 2.4 fold during this period and expenditure increased 2.6 fold

- Consequently, reimbursed expenditure (Euros/ 1000 inhabitants/ year) in Ireland in 2007 was over 10 fold greater at over $€ 60,000$ versus $€ 5832$ for Sweden 
Initiatives to increase the prescribing of low cost generics; the case of Scotland in the international context

- Netherlands (102)

- Aggressive measures to lower generic prices coupled with multiple demand side measures in the Netherlands, including education, economic and engineering initiatives, (Section 3.1 ), led to low utilisation of esomeprazole stabilising at $15 \%$ of total PPI utilisation in 2010

- As a result, reimbursed expenditure for the PPIs fell by $58 \%$ in 2010 compared with 2000 despite a 3 fold increase in utilisation

The situation in Ireland compares with Norway where esomeprazole dominated PPI prescribing shortly after its launch with

limited demand-side measures (138). There was though increasing utilisation of pantoprazole especially after the introduction of prescribing restrictions for esomeprazole and the preferred product status for pantoprazole in February 2007. The utilisation of esomeprazole fell after this although rose again in 2009 compared with 2008 (Table 4). This was perhaps not surprising as specialists in Norway have to verify the diagnosis and recommend therapy before PPIs can be reimbursed, and they were not subject to these restrictions. In addition, prescribing by physicians in ambulatory care is principally on trust, with limited follow by the health authorities, and they are reluctant to change prescriptions emanatingfrom specialists (138).

Table 4 - Utilisation of PPIs in Norway 2001 to 2009 (DDDs/ 1000 inhabitants/ day-138)

\begin{tabular}{|l|c|c|c|c|c|c|}
\hline & $\mathbf{2 0 0 1}$ & $\mathbf{2 0 0 3}$ & $\mathbf{2 0 0 5}$ & $\mathbf{2 0 0 7}$ & $\mathbf{2 0 0 8}$ & $\mathbf{2 0 0 9}$ \\
\hline Omeprazole & 8.98 & 5.03 & 4.38 & 5.61 & 6.42 & 6.67 \\
\hline Esomeprazole & 3.6 & 10.17 & 13.64 & 13.73 & 13.4 & 14.34 \\
\hline Pantoprazole & 0.25 & 0.5 & 0.8 & 4.32 & 6.77 & 8.18 \\
\hline Lanzoprazole & 4.04 & 4.75 & 5.66 & 6.13 & 6.49 & 6.53 \\
\hline Total PPIs & 16.87 & 20.45 & 24.48 & 29.79 & 33.08 & 35.72 \\
\hline
\end{tabular}

\subsubsection{Renin-angiotensin inhibitors across Europe}

\subsubsection{Angiotensin converting enzyme inhibitors (ACEIs)}

ACEIs can produce a cough in some patients, which can be bothersome. This argument has been used as the main justification for increasing the prescribing of ARBs (188, 189), which are typically substantially more expensive than generic ACEIs although the effectiveness and safety of both are similar $(111,190)$. Nevertheless, prospective clinical studies had shown coughing only occurs in approximately $10 \%$ of patients, and only $2 \%$ to $3 \%$ of patients in ACEI clinical trials actually discontinued treatment due to coughing $(111,189)$. As a result, considerable resources can be conserved with limiting the prescribing of patented angiotensin receptor blockers (ARBs) versus generic ACEIs as seen for instance in Austria, Croatia and Scotland (111).

The introduction of prescribing restrictions for patented ARBs in Austria and Croatia restricting their prescribing to patients intolerant to ACEIs, such as those with excessive coughing, limited their utilisation in practice (111). This compares with Portugal with appreciably higher utilisation of ARBs in 2007 with limited demand-side measures combating ARB manufacturers ${ }^{\text {ee }}$ marketing activities (Table 5). Low ARB 
Initiatives to increase the prescribing of low cost generics; the case of Scotland in the international context

utilisation was also seen in Scotland with multiple initiatives to encourage the prescribing of low cost generic ACEIs first line (111). There was greater follow-up of prescribing restrictions in Croatia compared with Austria, which included access to patients $^{\text {ee }}$ histories to check for abuse coupled with potential fines for physicians if this was seen. As a result, more limited utilisation of ARBs in Croatia compared with Austria between 2001 and 2007 (Table 5) $(101,111)$.

Table 5 - ARB utilisation as a percentage of total renin-angiotensin utilisation (in DDDs) 2001 to 2007 (adapted from $(101,111)$ ).

\begin{tabular}{|l|c|c|c|c|c|c|c|}
\hline & $\mathbf{2 0 0 1}$ & $\mathbf{2 0 0 2}$ & $\mathbf{2 0 0 3}$ & $\mathbf{2 0 0 4}$ & $\mathbf{2 0 0 5}$ & $\mathbf{2 0 0 6}$ & $\mathbf{2 0 0 7}$ \\
\hline Austria & 15.3 & 17.9 & 18.9 & 20.7 & 22.4 & 23.6 & 24.8 \\
\hline Scotland & 11.6 & 12.9 & 14.5 & 16.1 & 17.2 & 18.2 & 18.8 \\
\hline Croatia & 2.1 & 2.5 & 5.8 & 9.2 & 11.8 & 14.0 & 13.2 \\
\hline Portugal & 19.8 & 24.7 & 29.1 & 33.3 & 36.4 & 40.2 & 44.5 \\
\hline
\end{tabular}

These various measures resulted in reimbursed expenditure (Euros/ 1000 inhabitants/year) remaining relatively stable in Austria, Croatia and Scotland for the renin-angiotensin inhibitor drugs during this period despite increasing volumes (111), e.g. the utilisation of renin-angiotensin inhibitors increased $159 \%$ from 2001 to 2007 in Scotland during this period (101, 111). This compares with Portugal where expenditure increased by $155 \%$ during this period (111).

Prescribing restrictions for ARBs were also introduced in the Republic of Srpska (122). These included patients experiencing unwanted side-effects with ACEIs, specialist recommendation for switching, monitoring of restrictions by pharmacists before dispensing and a 50\% co-payment for selected ARBs otherwise $100 \%$ copayment. These combined activities limited ARB prescribing in practice in the Republic to $2 \%$ of total renin-angiotensin inhibitors in 2010 (122). Similarly, appreciably higher co-payments for the ARBs in Serbia (50\%) due to higher requested acquisition costs than generic ACEIs, compared with a copayment of 50 cents/ pack for ACEIs, resulted in ARBs again only accounting for
$2 \%$ of total renin-angiotensin inhibitor drugs in Serbia in 2011 (190).

\subsubsection{Angiotensin receptor blockers (ARBs)}

There were considerable activities in Austria, Belgium, Denmark, and Sweden, to enhance the prescribing of generic losartan versus patented ARBs following their availability, with limited measures in countries such as Scotland (110). Activities included (110, 128, 131, 142, 191):

- Austria - economics and enforcement including prescribing restrictions removed for losartan but not the other ARBs with potential financial sanctions for physicians for abuse

- Belgium - economics and enforcement physician prior approval needed to prescribe patented ARBs else $100 \%$ copayment; prescribing restrictions lifted forlosartan

- Denmark - enforcement - delisting of all ARBs other than losartan from the reimbursedlist

- Sweden - education, engineering, economics and enforcement including academic detailing, prescribing targets, therapeutic switching, financial 
Initiatives to increase the prescribing of low cost generics; the case of Scotland in the international context

incentives, and prescribing restrictions lifted for losartan but not patented ARBs

These initiatives resulted in ARB expenditure in Sweden falling by $26 \%$ by August 2011 (accumulated 6-monthly basis) despite a $16 \%$ increase in overall utilisation versus the pre-patent loss situation (128).

However, there were limited demand-side measures in countries such as Scotland (152). This is because the Health Boards already had a number of quality initiatives in place, they did not want to confuse physicians from encouraging ACEIs first line, they would obtain appreciable savings from generic losartan with high INN use and associated low prices (Tables 1 and 3), and other ARBs would shortly lose their patent (152). As a result, there was no change in the prescribing of losartan as a percentage of total ARB in Scotland versus the other European countries with active measures in place, which were all significant $(110,128,131,142,191)$ (Figure $1)$.

Figure 1 - Prescribing of losartan as a percentage of total ARBs (DDD basis) before and after the availability of generic losartan (Month 0) (adapted from (110))

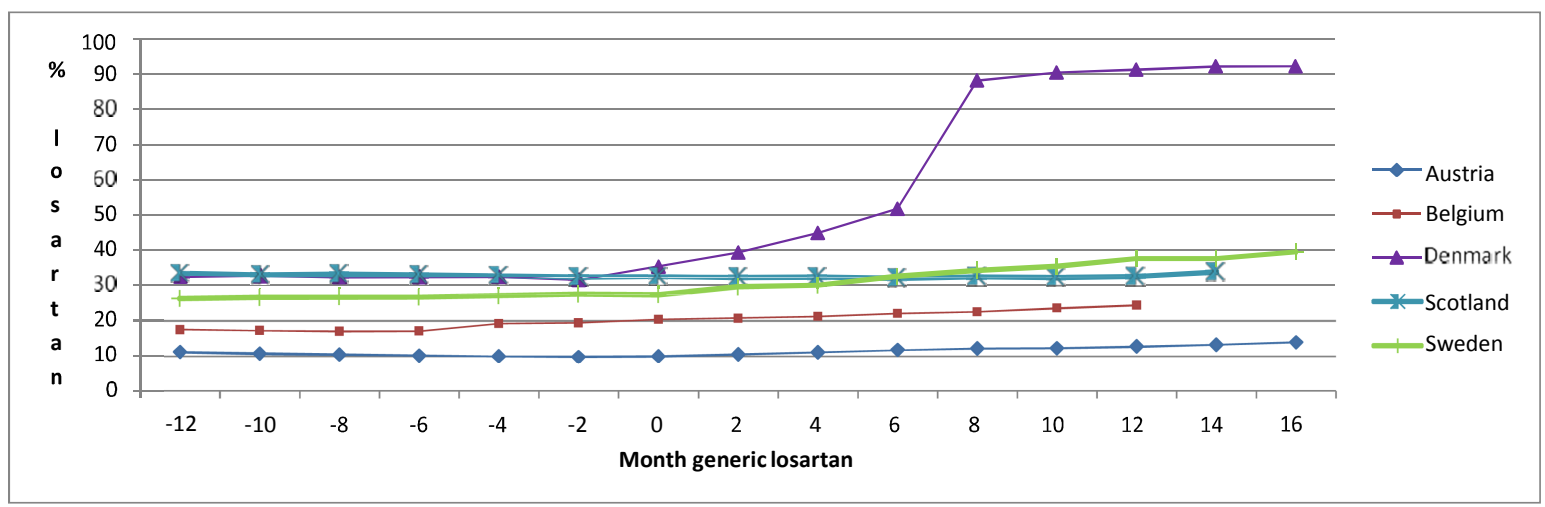

A similar situation was seen in England to Scotland until active switching policies were instigated (129).

\subsubsection{Statins across Europe excluding Scotland}

Again, multiple demand-side initiatives were instigated by a number of European countries to increase the prescribing of generic versus patented statins, combined with measures to lower generic prices (Section 3.1), to enhance prescribing efficiency. This was because the various statins were seen as essentially similar by health authorities at therapeutic doses $(10$, 108, 186, 192).
Typically, countries that again instigated multiple policies limited the prescribing of patented statins versus those countries with more limited demand-side measures $(1,10$, 108). This is illustrated by:

- Sweden versus Ireland $(10,108)$

- Multiple demand-side measures in Sweden (Education, economics and engineering) resulted in simvastatin utilisation increasing to $74 \%$ of total statin utilisation by the end of 2007 with patented statins (atorvastatin and rosuvastatin) limited to $21 \%$ totalutilisation

- Again limited demand-side measures in Ireland resulted in the utilisation of atorvastatin and rosuvastatin rising appreciably in Ireland 
Initiatives to increase the prescribing of low cost generics; the case of Scotland in the international context

following generic simvastatin. These two statins combined accounted for nearly $80 \%$ of total statin utilisation (DDD basis) in Ireland in 2007 (GMS population)

- This resulted in reimbursed expenditure in Ireland increasing 4.9 fold between 2001 and 2007 with utilisation increasing 7.3 fold, compared with a $39 \%$ reduction in reimbursed expenditure in Sweden alongside a 3.2 fold increase in utilisation

- As a result, reimbursed expenditure (Euros/ 1000 inhabitants/ year) in Ireland in 2007 for the statins was again over $€ 60,000$ versus $€ 5,192$ for Sweden

- Netherlands (102)

- Again multiple demand side measures to limit the prescribing of patented statins, with atorvastatin comprising only $27 \%$ of total statin utilisation (DDD basis) in 2010

- This coupled with supply side measures to lower generic prices (Section 3.1.1) resulted in reimbursed expenditure for the statins falling by $14 \%$ in 2010 vs. 2000 in the Netherlands despite a 3.8 fold increase in utilisation

- Austria and Norway $(59,138,193)$

- Prescribing restrictions were introduced for patented statins in both Austria and Norway to limit the prescribing of patented statins following the availability of generic simvastatin

- In Austria, physicians needed the permission of the Chief Medical Officer of their Social Insurance Fund for atorvastatin to be reimbursed, otherwise $100 \%$ copayment

- In Norway, active therapeutic switching was encouraged alongside prescribing restrictions. However, this was principally on trust as again limited follow up of physician prescribing by the health authorities. However, physicians needed health authority permission if they wished to prescribe lower strength atorvastatin (10 and 20mg) and patients be reimbursed

- As a result of the differences in the follow-up of the restrictions, utilisation of patented statins fell from $31.6 \%$ of total statins in 2003 (year before restrictions - DDD based) in Austria to $10.9 \%$ in 2007, a $66 \%$ reduction. In Norway, their utilisation fell from $46.2 \%$ of total statins (full year before restrictions) in 2004 to $26.2 \%$ in 2008, a reduction of $44 \%$

\subsubsection{Atypical antipsychotics}

It is generally recognised by health authorities that there are classes where it can be difficult for them to instigate demandside measures to try and increase the prescribing of generics versus patented products in a class. One such class is the atypical antipsychotic drugs for treating schizophrenia and bipolar disease. Experts, as well as health authorities, suggest treatment should be tailored to individual patients (194-196).

This was seen in practice in a recent study, which showed a consistent decrease in risperidone utilisation among European countries as a percentage of selected atypical antipsychotics (DDD basis) following the availability of generic risperidone (113, 153, 161, 196, 197). Consequently, health authorities generally need to wait until more atypical antipsychotics lose their patents before they see significant reductions in expenditure, which is already happening (196). The only exceptions to this are initiatives to enhance the prescribing of different formulations 
Initiatives to increase the prescribing of low cost generics; the case of Scotland in the international context

where generic availability changes their value. This was seen in Belgium where there has been greater scrutiny over the prescribing of more expensive long-acting risperidone injections following oral generic risperidone at appreciably lower costs (197). This resulted in its reduced utilisation in recent years versus other formulations of risperidone, which is continuing (197).

\subsubsection{Prescribing restrictions}

As seen in Table 5 and Section 3.3.2.1, restricting the prescribing of ARBs in Austria, Croatia, and the Republic of Srpska, appreciably limited their prescribing versus countries with limited demand-side measures, e.g. Portugal. The prescribing restrictions for patented statins in Austria also appreciably reduced their utilisation (Section3.3.3).

However, the greater intensity of follow-up of ARB prescribing restrictions in Croatia and the Republic of Srpska, resulted in greater utilisation of generic ACEIs in Croatia and the Republic of Srpska versus Austria. Similarly greater follow-up of prescribing restrictions for patented statins in Austria compared with Norway resulted in appreciably lower utilisation of patented statins in Austria $(111,122,138)$. Limited follow-up of prescribing restrictions for esomeprazole in Norway (Section 3.3.1) also resulted in greater utilisation of esomeprazole than initially envisaged(138).

A similar situation was seen in Sweden where the authorities restricted the prescribing of patented duloxetine following the availability of generic venlafaxine as its effectiveness and cost could not justify first line use (112). However, there was limited follow-up of the prescribing restrictions among the authorities in practice. This resulted in no change in duloxetine utilisation (DDD basis). However, there was a significant increase in the utilisation of venlafaxine post duloxetine restrictions (112).

The timing of prescribing restrictions is also important. Prescribing restrictions were recently introduced for patented statins in Sweden. However, they had limited influence on subsequent utilisation patterns in practice (198). This may be due to the fact that they were introduced some six years after intensive activities to encourage the preferential prescribing of generic statins (Section 3.3.3) (108).

\subsubsection{Scotland}

\section{- PPIs}

There was typically limited prescribing of patented esomeprazole in Scotland in recent years with multiple demand-side measures, which included formularies, academic detailing, prescribing targets and financial incentives (132). As a result, esomeprazole comprised only $5.3 \%$ to $7.1 \%$ of total PPI utilisation (DDD basis) between 2002 and 2010 compared with omeprazole, which comprised $67 \%$ of total PPI utilisation in 2010(132).

This has continued with esomeprazole comprising $7.7 \%$ in 2011 and $6.4 \%$ in 2012 of total omeprazole and esomeprazole, i.e. before generic esomeprazole utilisation became available, versus $6.29 \%$ in 2002 (items dispensed).

As a result of these initiatives, coupled with measures to lower the price of generics (Table 1) and ensure high INN prescribing (Table 3), PPI expenditure fell from GB£56.49 million in 2001 in Scotland to GB£18.06 million in 2015, a drop of $68 \%$. At the same time, utilisation increased 2.91 fold to 5.23 million items dispensed in 2015. Reimbursed expenditure for the PPIs in 2015 would have been GB£146.18 million greater assuming no generic PPIs 
Initiatives to increase the prescribing of low cost generics; the case of Scotland in the international context

and theaverage cost/item dispensed in 2015 remained at 2001 levels.

\section{- SSRIs}

Multiple demand side initiatives in Scotland between 2001 and 2007 limited the prescribing of escitalopram compared with countries with less demand side measures (101). For example, escitalopram comprised $27.1 \%$ of total SSRI prescribing in Ireland by the end of 2007 versus only $7.0 \%$ in Scotland. As a result, SSRI expenditure fell by $59 \%$ in Scotland in 2007 compared with 2001 but increased by $72 \%$ in Ireland. This was despite a 2.37 fold increase in SSRI utilisation during this period in Scotland (101).

The same prescribing patterns have continued with anything a reduction in the utilisation of escitalopram over time from $15.6 \%$ of total citalopram and escitalopram use in 2007 to $7.3 \%$ in 2012, 6.4\% in 2013 and $5.8 \%$ in 2014. As a result of these initiatives, coupled with measures to lower the price of generics (Table 1) and ensure high INN prescribing (Table 3), SSRI expenditure fell from GB£28.937 million in 2011 to GB£11.551 million in 2015, a drop of $60.1 \%$. During this time, utilisation (items dispensed) increased from 1.3 9million in 2001 to 2.95 million in 2015 , and increase of $112 \%$.

\section{- Statins}

There again were multiple measures to increase the prescribing of multiple sourced (generic) statins. This resulted in simvastatin dominating statin utilisation, e.g. $57 \%$ to $58 \%$ of total statin utilisation (DDD basis) from 2007 to 2010. Concurrent with this, there was stabilisation of atorvastatin and rosuvastatin utilisation at $40 \%$ of total statin utilisation (132).
Since the availability of generic atorvastatin in 2012, its prescribing has appreciably increased as a result of initiatives to switch patients from rosuvastatin to atorvastatin as well as encourage the prescribing of simvastatin and atorvastatin first line, particularly higher strength atorvastatin (199-203). This led to the utilisation of rosuvastatin falling from 262,409 items dispensed in 2011 to 217,791 in 2015 in Scotland, a $16.8 \%$ fall, whilst the utilisation of atorvastatin rose from 1,149,459 items dispensed in 2011 to $1,637,000$ in 2015. As a result, the utilisation of rosuvstatin fell from $5.7 \%$ of total statins (items dispensed) in 2011 to $4.5 \%$ in 2015.

Following the variety of initiatives to increase the prescribing of low cost generic statins (Tables 1 and 3), statin expenditure in Scotland fell from GB£43.39 million in 2001 to GB£19.10 million in 2015, a drop of $56 \%$. At the same time, utilisation increased 4.03 fold to 4.89 million items dispensed in 2015. Reimbursed expenditure for the statins in 2015 would have been GB£155.80 million more assuming no generic statins and the average cost/ item dispensed in 2015 remained at 2001 levels.

\section{Discussionandconclusions}

Increasing the use of generics is essential to maintain equitable and comprehensive health care in Europe given increasing pressure on resources, with case histories demonstrating the extent of potential savings that can be achieved. Countries are learning from each other, and this will continue (1).

The first step in this process is ensuring good quality generics for patients as seen in Europe and the US. This can be achieved through strengthening the registration system, including factory inspections, and the tests performed in accordance with Kaplan et al and others (106). Regulations 


\section{Initiatives to increase the prescribing of low cost generics; the case of Scotland in the international context}

and initiatives supporting the production of good quality generics can also help countries with exports, which is a concern currently in countries such as Pakistan (78). Concurrent with this is education of all key stakeholder groups that there should be no difference in patient care once the quality of generics is assured. The ultimate aim is to achieve high INN prescribing rates as seen in the UK (Table 3) for the ARBs, PPIs, SSRIs and statins, which are very close to the $100 \%$ target set by the WHO (165). Encouraging INN prescribing is seen as beneficial to reduce patient confusion if different branded generics are dispensed at each occasion $(95,129)$. However, in some countries this will take time as current IT systems are based around branded generics, e.g. Sweden. Once instigated, apart from a small minority of clinically justified situations (Box 1), the focus should be on efficient registration and reimbursement systems as well as quality control.

The pricing of generics is also a key consideration to sustainability and affordability especially in LMICs, with companies now showing the way on potential low costs for producing oral generics with economies of scale (Section 3.1). The Netherlands, Scotland (Table 1) and Sweden (Section 3.1) provide examples of ways to lower prices of generics when linked to increased utilisation. However in a number of countries, this has to be balanced against supporting the development of local manufacturing facilities which can add to costs. In addition, low prices for generics have to be balanced against their availability (2). If prices of generics become too low, they become uneconomical making drug shortages more likely $(38,204)$.

Pricing policies for generics have to be thought through, and coupled with demandside measures, to ensure expectations are met. Otherwise there could be disappointment as seen in China with its current incentive systems (Section 3.2.3). Price cuts can bring about substantial savings; however, these are short lived without also looking at demand-side measures (75).

There are multiple ways that health authorities can increase the prescribing of generics versus originators (Table 2). As mentioned, encouraging INN prescribing is advocated by the WHO and others (165). This includes encouraging INN prescribing voluntarily through education of both health professionals and patients, and follow-up apart from a limited number of cases (Box 1 ), as seen in the UK (Table 1). Alternatively, mandating this as seen in Abu Dhabi and Lithuania $(125,130)$. However care is needed as seen in Abu Dhabi else again the envisaged goals will not be achieved (Section 3.2.4). A number of countries have also instigated compulsory generic substitution, including South Africa and Sweden $(140,159,170)$; alternatively encouraged pharmacists to substitute, e.g. France (Table 1) (136). Hasseli et al provide guidance (Box 2) for countries contemplatingsuchmeasures.

There are also multiple initiatives that can be introduced by health authorities to encourage the prescribing of multiple sourced products in a class versus patented ones (Section 3.3). As seen (Sections 3.1, 3.2 and 3.3), both supply as well as multiple demand-side reforms are essential to maximise prescribing efficiency. The multiple supply- and demand-side measures in Scotland have resulted in considerable savings (Section 3.2.6) for the various classes despite appreciably increased utilisation, providing direction to others. The multiple measures in Scotland also stabilised renin-angiotensin inhibitor expenditure between 2001 and 2007 despite a $159 \%$ increase in utilisation (Section 3.3.2.1). 


\section{Initiatives to increase the prescribing of low cost generics; the case of Scotland in the international context}

Demand-side measures appear to be complementary. Countries that have instigated only a limited number of demandside measures typically fail to combat pharmaceutical company pressure. This was seen in Ireland with the PPIs, SSRIs and statins versus Scotland and Sweden (3.3.1, 3.3.3, 3.3.6), Norway with esomeprazole even with prescribing restrictions (Table 4) and Portugal with the ARBs (Table 5). In Scotland, where there was no change in ARB prescribing patterns following generic losartan, with no specific activities encouraging its preferential prescribing versus patented ARBs (Figure 1) (152), suggests no ,,spill overe effect of health authority activities across classes even if they are closely related such as the reninangiotensin inhibitors. Physicians in Scotland were good at preferentially prescribing generic ACEIs versus patented ARBs (Table 5); however, this did not translate into increased prescribing of generic losartan versus patented ARBs when it became available. Overall, the multiple demand-side measures in Scotland to limit ARB prescribing appeared just as effective as prescribing restrictions with follow-up in Croatia (Table 5).

There are similar considerations when it comes to prescribing restrictions. These need to be followed up by health authorities to maximise their impact, else health authorities could be disappointed in the outcomes (Section 3.5). However, it is acknowledged there are some classes where it is difficult for health authorities to introduce multiple measures such as the atypical antipsychotics (Section 3.3.4)

Concentrating on one reform, i.e. either supply or demand side measures, but not both, can also reduce potential efficiency gains from the availability of generics. This was seen with price cuts in Korea for medicines to treat patients with hypercholesterolaemia which failed to achieve the desired results with appreciably increased use of atorvastatin following generics as well as more expensive lipid lowering drugs (205). In Germany in 2007, there was very limited utilisation of atorvastatin following reference pricing for the class in 2003 at just $2 \%$ of overall statin utilisation (185). This compares with $21 \%$ and $33 \%$ respectively on a DDD basis for atorvastatin and rosuvastatin in Sweden and England in 2007 (108). However, expenditures were similar or greater in Germany when adjusted for population sizes due to higher expenditure/ DDD for simvastatin.

Above all, the commitment of health authorities to promote the appropriate use of medicines including generics, coupled with the political will to pursue changes in existing pharmaceutical policies, is very important to achieve desired savings and medicine access.

We accept there are limitations with this paper. This includes the fact that we did not undertake a systematic review of published studies as many such reviews and meta analyses have already been performed. However in view of the consistency of our findings, we believe our findings are robust and provide direction to others.

In conclusion, multiple measures and initiatives are needed to ensure low cost for generics and enhance their utilisation versus originators and patented products in a class. This is essential to attain or ensure universal health care as well as increase affordability of medicines. Countries are learning from each other, and this will continue.

\section{Conflicts of interest}

Alec Morton is PI for his institution on a work package of a European project DRIVE-AB (Driving Re-Investment for $R \& D$ on Antibiotics) under the Innovative 
Initiatives to increase the prescribing of low cost generics; the case of Scotland in the international context

Medicines Initiative (IMI) https://www.imi.europa.eu/. DRIVE-AB is funded by the European Commission but receives in-kind support from pharmaceutical companies. He has no other conflicts of interest. The other authors have no other conflicts of interest to declare.

\section{References}

1. Godman B, Wettermark B, van Woerkom $\mathrm{M}$ et al. Multiple policies to enhance prescribing efficiency for established medicines in Europe with a particular focus on demand-side measures: findings and future implications. Frontiers inpharmacology. 2014;5:106.

2. Dylst P, Vulto A, Godman B, Simoens S. Generic medicines: solutions for a sustainable drug market? Applied health economics and health policy. 2013;11(5):437-43.

3. Patel A, Gauld R, Norris P, Rades T. Quality of generic medicines in South Africa: Perceptions versus Reality - A qualitative study. BMC health services research. 2012;12(1):297.

4. Malmstrom RE, Godman BB, Diogene E et al. Dabigatran - a case history demonstrating the need for comprehensive approaches to optimize the use of new drugs. Frontiers in pharmacology. 2013;4:39.

5. Garattini S, Bertele V, Godman B, Haycox A et al. Enhancing the rational use of new medicines across European health care systems. European journal of clinical pharmacology. 2008;64(12):1137-8.

6. Cameron A, Ewen M, Ross-Degnan $\mathrm{D}$ et al. Medicine prices, availability, and affordability in 36 developing and middleincome countries: a secondary analysis. Lancet. 2009;373(9659):240-9.

7. Cameron A, Mantel-Teeuwisse AK, Leufkens HG et al. Switching from originator brand medicines to generic equivalents in selected developing

\section{Acknowledgements}

Alec Morton and Axel Leporowski would like to thank that New Professore's Fund of Strathclyde University for its financial support.

countries: how much could be saved? Value inhealth. 2012;15(5):664-73.

8. Jamshed SQ, Hassali MA, Ibrahim MI e al. Knowledge attitude and perception of dispensing doctors regarding generic medicines in Karachi, Pakistan: a qualitative study.JPMA.2011;61(1):80-3.

9. Hassali MA, Alrasheedy AA, McLachlan A et al. The experiences of implementing generic medicine policy in eight countries: A review and recommendations for a successful promotion of generic medicine use. Saudi pharmaceutical journal. 2014;22(6):491503.

10. Godman B, Shrank W, Andersen M et al. Policies to enhance prescribing efficiency in europe: findings and future implications. Frontiers in pharmacology. 2010;1:141.

11. Zucman D, Camara S, Gravisse $\mathbf{J}$ et al. Generic antiretroviral drugs in developing countries: friends or foes? AIDS. 2014;28(4):607-9.

12. Castro A, Westerhaus M. Access to generic antiretrovirals: inequality, intellectual property law, and international trade agreements. Cadernos de saude publica. 2007;23 Suppl 1:S85-96.

13. Wainberg MA. Generic HIV drugs-enlightened policy forglobal health. NEJM. 2005;352(8):747-50.

14. Havlir DV, Hammer SM. Patents versus patients? Antiretroviral therapy in India. NEJM. 2005;353(8):749-51.

15. Simmons K. Sub-Saharan Africa makes progress against poverty but has long way to go. Available at URL: 
Initiatives to increase the prescribing of low cost generics; the case of Scotland in the international context

http://www.pewresearch.org/facttank/2015/09/24/sub-saharan-africa-makesprogress-against-poverty-but-has-long-wayto-go/.

16. Bourgeois A, Laurent C, Mougnutou $\mathrm{R}$ et al. Field assessment of generic antiretroviral drugs: a prospective cohort study in Cameroon. Antiviral therapy. 2005;10(2):335-41.

17. Laurent C, Kouanfack C, KoullaShiro S et al. Effectiveness and safety of a generic fixed-dose combination of nevirapine, stavudine, and lamivudine in HIV-1-infected adults in Cameroon: openlabel multicentre trial. Lancet. 2004;364(9428):29-34.

18. Hemanth Kumar AK, Ramachandran G, Rajasekaran S et al. Pharmacokinetics of lamivudine \& stavudine in generic fixeddose combinations in HIV-1 infected adults in India. The Indian journal of medical research. 2009;130(4):451-7.

19. Crane JT, Kawuma A, Oyugi JH, Byakika JT et al. The price of adherence: qualitative findings from HIV positive individuals purchasing fixed-dose combination generic HIV antiretroviral therapy in Kampala, Uganda. AIDS and behavior. 2006;10(4):437-42.

20. Kumarasamy N, Solomon S, Chaguturu SK et al. The changing natural history of HIV disease: before and after the introduction of generic antiretroviral therapy in southern India. Clinical infectious diseases. 2005;41(10):1525-8.

21. Venkatesh M, Bairavi VG, Sasikumar KC. Generic antibiotic industries: Challenges and implied strategies with regulatory perspectives. Journal of Pharmacy and Bioallied Sciences. 2011;3(1):101-8.

22. Md Rezal RS, Hassali MA, Alrasheedy AA et al. Physicians' knowledge, perceptions and behaviour towards antibiotic prescribing: a systematic review of the literature. Expert review of anti-infective therapy. 2015;13(5):665-80.
23. Hill A, Gotham D, Fortunak J et al. Target prices for mass production of tyrosine kinase inhibitors for global cancer treatment. BMJ open. 2016;6(1):e009586.

24. Yang YT, Nagai S, Chen BK et al. Generic oncology drugs: are they all safe? The lancet oncology. 2016;17(11):e493e501.

25. Tefferi A, Kantarjian H, Rajkumar SV et al. In Support of a Patient-Driven Initiative and Petition to Lower the High Price of Cancer Drugs. Mayo Clinic proceedings Mayo Clinic. 2015.

26. Ghinea N, Kerridge I, Lipworth W. If we don "t talk about value, cancer drugs will become terminal for health systems. Available at URL: http://theconversation.com/if-we-dont-talkabout-value-cancer-drugs-will-becometerminal-for-health-systems-44072

27. Howard DH, Bach P, Berndt ER et al. Pricing in the Market for Anticancer Drugs. Journal of Economic Perspectives. 2015;29(1):139-62.

28. Hedegaard U, Kjeldsen LJ, Pottegard A, et al. Improving Medication Adherence in Patients with Hypertension: A Randomized Trial. The American journal of medicine. 2015;128(12):1351-61.

29. Qvarnstrom M, Kahan T, Kieler H et al. Persistence to antihypertensive drug treatment in Swedish primary healthcare. European journal of clinical pharmacology. 2013;69(11):1955-64.

30. Bezie $\mathrm{Y}$, Molina $\mathrm{M}$, Hernandez $\mathrm{N}$ et al. Therapeutic compliance: a prospective analysis of various factors involved in the adherence rate in type 2 diabetes. Diabetes \& metabolism. 2006;32(6):611-6.

31. Cramer JA, Benedict A, Muszbek N et al. The significance of compliance and persistence in the treatment of diabetes, hypertension and dyslipidaemia: a review. International journal of clinical practice. 2008;62(1):76-87.

32. Simpson RJ, Jr., Mendys P. The effects of adherence and persistence on clinical outcomes in patients treated with 
Initiatives to increase the prescribing of low cost generics; the case of Scotland in the international context

statins: a systematic review. Journal of clinical lipidology. 2010;4(6):462-71.

33. Mills EJ, Bakanda C, Birungi J et al. Life expectancy of persons receiving combination antiretroviral therapy in lowincome countries: a cohort analysis from Uganda. Annals of internal medicine. 2011;155(4):209-16.

34. Hansana V, Sanchaisuriya P, Durham $\mathrm{J}$ et al. Adherence to antiretroviral therapy (ART) among people living with HIV (PLHIV): a cross-sectional survey to measure in Lao PDR. BMC public health. 2013;13:617.

35. Simoens S, Sinnaeve PR. Patient copayment and adherence to statins: a review and case studies. Cardiovascular drugs and therapy. 2014;28(1):99-109.

36. Shrank WH, Hoang T, Ettner SL et al. The implications of choice: prescribing generic or preferred pharmaceuticals improves medication adherence for chronic conditions. Archives of internal medicine. 2006;166(3):332-7.

37. Barbui C, Conti V. Adherence to generic $\mathrm{v}$. brand antidepressant treatment and the key role of health system factors. Epidemiology and psychiatric sciences. 2015;24(1):23-6.

38. Kalo Z, Holtorf AP, AlfonsoCristancho R, et al. Need for multicriteria evaluation of generic drug policies. Value in health. 2015;18(2):346-51.

39. Briesacher BA, Gurwitz JH, Soumerai SB. Patients at-risk for costrelated medication nonadherence: a review of the literature. Journal of general internal medicine. 2007;22(6):864-71.

40. Briesacher BA, Andrade SE, Fouayzi $\mathrm{H}$ e al. Medication adherence and use of generic drug therapies. The American journal of managed care. 2009;15(7):450-6.

41. Dylst P, Vulto A, Simoens S. Societal value of generic medicines beyond cost-saving through reduced prices. Expert review of pharmacoeconomics \& outcomes research. 2015;15(4):701-11.
42. Eaddy MT, Cook CL, O'Day K et al How patient cost-sharing trends affect adherence and outcomes: a literature review. P \& T. 2012;37(1):45-55.

43. Maciejewski ML, Farley JF, Parker J et al. Copayment reductions generate greater medication adherence in targeted patients. Health affairs. 2010;29(11):2002-8.

44. Babazono A, Miyazaki M, Imatoh T et al. Effects of the increase in co-payments from 20 to 30 percent on the compliance rate of patients with hypertension or diabetes mellitus in the employed health insurance system. International journal of technology assessment in health care. 2005;21(2):228-33.

45. Doshi JA, Zhu J, Lee BY et al. Impact of a prescription copayment increase on lipid-lowering medication adherence in veterans. Circulation. 2009;119(3):390-7.

46. Choudhry NK, Denberg TD, Qaseem A. Improving Adherence to Therapy and Clinical Outcomes While Containing Costs: Opportunities From the Greater Use of Generic Medications: Best Practice Advice From the Clinical Guidelines Committee of the American College of Physicians. Annals of internal medicine. 2016;164(1):41-9.

47. Yamada M, Welty TE. Generic substitution of antiepileptic drugs: a systematic review of prospective and retrospective studies. The Annals of pharmacotherapy. 2011;45(11):1406-15.

48. Privitera MD, Welty TE, Gidal BE et al. Generic-to-generic lamotrigine switches in people with epilepsy: the randomised controlled EQUIGEN trial. Lancet neurology. 2016;15(4):365-72.

49. Kesselheim AS, Misono AS, Lee JL et al. Clinical equivalence of generic and brand-name drugs used in cardiovascular disease: a systematic review and metaanalysis. JAMA. 2008;300(21):2514-26.

50. Kesselheim AS, Stedman MR, Bubrick EJ et al. Seizure outcomes following the use of generic versus brandname antiepileptic drugs: a systematic 
Initiatives to increase the prescribing of low cost generics; the case of Scotland in the international context

review and meta-analysis. Drugs. 2010;70(5):605-21.

51. Gagne JJ, Kesselheim AS, Choudhry NK et al. Comparative effectiveness of generic versus brand-name antiepileptic medications. Epilepsy \& behavior 2015;52(Pt A):14-8.

52. Gagne JJ, Choudhry NK, Kesselheim AS et al. Comparative effectiveness of generic and brand-name statins on patient outcomes: a cohort study. Annals of internal medicine. 2014;161(6):400-7.

53. Corrao G, Soranna D, Arfe A, Casula $\mathrm{M}$ et al. Are generic and brand-name statins clinically equivalent? Evidence from a real data-base. European journal of internal medicine. 2014;25(8):745-50.

54. Veronin M. Should we have concerns with generic versus brand antimicrobial drugs? A review of issues. JPHSR 2011;2:135-50.

55. Corrao G, Soranna D, Merlino L et al. Similarity between generic and brandname antihypertensive drugs for primary prevention of cardiovascular disease: evidence from a large population-based study. European journal of clinical investigation. 2014;44(10):933-9.

56. Lessing C, Ashton T, Davis P. The impact on health outcomes and healthcare utilisation of switching to generic medicines consequent to reference pricing: the case of lamotrigine in new zealand. Applied health economics and health policy. 2014;12(5):537-46.

57. Paton C. Generic clozapine: outcomes after switching formulations. The British journal of psychiatry. 2006;189:1845.

58. Araszkiewicz AA, Szabert K, Godman B et al. Generic olanzapine: health authority opportunity or nightmare? Expert review of pharmacoeconomics \& outcomes research. 2008;8(6):549-55.

59. Sakshaug S, Furu K, Karlstad O et al. Switching statins in Norway after new reimbursement policy: a nationwide prescription study. British journal of clinical pharmacology. 2007;64(4):476-81.

60. Talati R, Scholle JM, Phung OP et al. Efficacy and safety of innovator versus generic drugs in patients with epilepsy: a systematic review. Pharmacotherapy. 2012;32(4):314-22.

61. Baumgärtel $\mathrm{C}$, Godman $\mathrm{B}$, Malmström $\mathrm{R}$ et al. What lessons can be learned from the launch of generic clopidogrel? GaBI Journal. 2012;1(2):5868.

62. Desmarais JE, Beauclair L, Margolese HC. Switching from brand-name to generic psychotropic medications: a literature review. CNS neuroscience \& therapeutics. 2011;17(6):750-60.

63. Fadare JO, Adeoti AO, Desalu OO et al. The prescribing of generic medicines in Nigeria: knowledge, perceptions and attitudes of physicians. Expert review of pharmacoeconomics \& outcomes research. 2016;16(5):639-50.

64. Cessak G, Rokita K, Dabrowska M et al. Therapeutic equivalence of antipsychotics and antidepressants - A systematic review. Pharmacological reports. 2016;68(2):217-23.

65. Editorial. Generic bashing: effective but illegal. PRESCRIRE INTERNATIONAL 2013;22(144):307. 66. Van Ameringen M, Mancini C, Patterson B et al. Symptom relapse following switch from Celexa to generic citalopram: an anxiety disorders case series. Journal of psychopharmacology. 2007;21(5):472-6.

67. Hassali MA, Wong ZY, Alrasheedy AA et al. Perspectives of physicians practicing in low and middle income countries towards generic medicines: a narrative review. Health policy. 2014;117(3):297-310.

68. Toverud EL, Hartmann K, Hakonsen H. A Systematic Review of Physicians' and Pharmacists' Perspectives on Generic Drug Use: What are the Global Challenges? 
Initiatives to increase the prescribing of low cost generics; the case of Scotland in the international context

Applied health economics and health policy. 2015 Aug;13 Suppl 1:S35-45.

69. Fitzgerald CL, Jacobson MP. Generic substitution of levetiracetam resulting in increased incidence of breakthrough seizures. The Annals of pharmacotherapy. 2011;45(5):e27.

70. Heaney DC, Sander JW. Antiepileptic drugs: generic versus branded treatments. Lancet neurology. 2007;6(5):465-8.

71. Dunne S, Shannon B, Dunne C, Cullen W. A review of the differences and similarities between generic drugs and their originator counterparts, including economic benefits associated with usage of generic medicines, using Ireland as a case study. BMC pharmacology \& toxicology. 2013;14:1.

72. Chua GN, Hassali MA, Shafie AA, Awaisu A. A survey exploring knowledge and perceptions of general practitioners towards the use of generic medicines in the northern state of Malaysia. Health policy. 2010;95(2-3):229-35.

73. Drozdowska A, Hermanowski T. Exploring the opinions and experiences of patients with generic substitution: a representative study of Polish society. International journal of clinical pharmacy. 2015;37(1):68-75.

74. Kumar R, Hassali MA, Saleem F, Alrasheedy AA et al. Knowledge and perceptions of physicians from private medical centres towards generic medicines: a nationwide survey from Malaysia. Journal of pharmaceutical policy and practice. 2015;8(1):11.

75. Kwon HY, Kim H, Godman B et al. The impact of South Korea's new drugpricing policy on market competition among off-patent drugs. Expert review of pharmacoeconomics \& outcomes research. 2015;15(6):1007-14.

76. Tsiantou V, Zavras D, Kousoulakou $\mathrm{H}$ et al. Generic medicines: Greek physicians' perceptions and prescribing practices. Journal of clinical pharmacy and therapeutics. 2009;34(5):547-54.

77. Colgan S FK, Martin LR, Stephens et al. Perceptions of generic medication in the general population, doctors and pharmacists: a systematic review. BMJ open. 2015;5:e008915.

doi:10.1136/bmjopen-2015-.

78. Khan B, Godman B, Babar A et al. Assessment of active pharmaceutical ingredients in the registration procedures in Pakistan: implications for the future. GaBI Journal 2016;5(4):156-63.

79. Ferner RE, Lenney W, Marriott JF. Controversy over generic substitution. BMJ. 2010;340:c2548.

80. Duerden MG, Hughes DA. Generic and therapeutic substitutions in the UK: are they a good thing? British journal of clinical pharmacology. 2010;70(3):335-41.

81. Godman B, Wettermark B, Hoffmann $M$ et al. Multifaceted national and regional drug reforms and initiatives in ambulatory care in Sweden: global relevance. Expert review of pharmacoeconomics \& outcomes research. 2009;9(1):65-83.

82. Grandia L VA. Generics substitution in primary care: summary of the Dutch community pharmacies guidelines. Generics and Biosimilars Initiative Journal (GaBI Journal). 2012;1(2):102-3.

83. Taube D, Jones $\mathrm{G}, \mathrm{O}$ 'Beirne $\mathrm{J}$ et al. Generic tacrolimus in solid organ transplantation. Clinical transplantation. 2014;28(5):623-32.

84. Godman B, Baumgartel C. Are generic immunosuppressants safe and effective? BMJ. 2015;350:h3248.

85. Gothe H, Schall I, Saverno K et al. The Impact of Generic Substitution on Health and Economic Outcomes: A Systematic Review. Applied health economics and health policy. 2015;13 Suppl 1:S21-33.

86. Vogler S, Zimmerman N, LeopoldC et al. Discounts and Rebates Granted for Medicines for Hospital Use in Five 
Initiatives to increase the prescribing of low cost generics; the case of Scotland in the international context

European Countries. The Open Pharmacoeconomics \& Health Economics Journal. 2013;5:1-10.

87. Vogler S, Zimmermann N, Habl C et al. The role of discounts and loss leaders in medicine procurement in Austrian hospitals - a primary survey of official and actual medicine prices. Cost effectiveness and resource allocation 2013;11(1):15.

88. Bjorkhem-Bergman L, AndersenKarlsson $\mathrm{E}$ et al. Interface management of pharmacotherapy. Joint hospital and primary care drug recommendations. European journal of clinical pharmacology. 2013;69 Suppl 1:73-8.

89. Vernaz N, Haller G, Girardin F et al. Patented drug extension strategies on healthcare spending: a cost-evaluation analysis. PLoS medicine. 2013;10(6):e1001460.

90. Godman B, Wilcock M, Martin A et al. Generic pregabalin; current situation and implications for health authorities, generics and biosimilars manufacturers in the future. GaBIJournal. 2015;4(3):125-35.

91. Editorial. European patent will make medicines cheaper GaBI. Available at URL: http://www.gabionline.net/index.php/Pharm a-News/European-patent-will-makemedicines-cheaper.

92. Law360. Highlighting 'Pay For Delay' Concerns. Available at URL: https://www.law360.com/articles/302521/hi ghlighting-pay-for-delay-concerns.

93. Editorial. How originatorcompanies delay generic medicines. Available atURL: http://gabionline.net/Reports/Howoriginator-companies-delay-genericmedicines.

94. Godman B, Campbell S, Suh HS et al. Ongoing measures to enhance prescribing efficiency across Europe: implications for other countries. J Health Tech Assess 2013;1:27-42.

95. Olsson E, Ingman P, Ahmed B et al. Pharmacist-patient communication in Swedish community pharmacies. RSAP. 2014;10(1):149-55.
96. Rathe J, Sondergaard J, Jarbol DE et al. Patients' concern about their medicine after a generic switch: a combined crosssectional questionnaire and register study. Pharmacoepidemiology and drug safety. 2014;23(9):965-73.

97. Simoens S. A reviewof generic medicine pricing in Europe. GaBI. 2012;1(1):8-12.

98. Vogler S. How large are the differences between originator and generic prices? Analysis of five molecules in 16 European countries. Farmeconomia Health economics and therapeutic pathways 2012;13(Suppl 3):29-41.

99. Vogler S. The impact of pharmaceutical pricing and reimbursement policies on generics uptake: implementation of policy options on generics in 29 European countries-an overview. GaBI Journal. 2012;1(2):93-100.

100. Truter I, Shankar S, Bennie M et al. Initiatives in South Africa to enhance the prescribing of generic proton pump inhibitors: findings and implications. Journal of comparative effectiveness research. 2015;4(2):123-31.

101. Godman B, Bishop I, Finlayson AE et al. Reforms and initiatives in Scotland in recent years to encourage the prescribing of generic drugs, their influence and implications for other countries. Expert review of pharmacoeconomics \& outcomes research. 2013;13(4):469-82.

102. Woerkom $\mathrm{M}$, Piepenbrink $\mathrm{H}$, Godman B et al. Ongoing measures to enhance the efficiency of prescribing of proton pump inhibitors and statins in The Netherlands: influence and future implications. Journal of comparative effectiveness research. 2012;1(6):527-38.

103. Godman B, Abuelkhair M, Vitry A et al. Payers endorse generics to enhance prescribing efficiency; impact and future implications, a case history approach. GaBI journal. 2012;1(2):21-35.

104. Dylst P, Vulto A, Simoens S. Demand-side policies to encourage the use 
Initiatives to increase the prescribing of low cost generics; the case of Scotland in the international context

of generic medicines: an overview. Expert review of pharmacoeconomics \& outcomes research. 2013;13(1):59-72.

105. Vogler S, Zimmerman N. How do regional sickness funds encourage more rational use of medicines, including the increase of generic uptake? A case study from Austria. Generics and Biosimilars Initiative Journal 2013;2(2):65-75.

106. Kaplan WA, Ritz LS, Vitello $M$ et al. Policies to promote use of generic medicines in low and middle income countries: a review of published literature, 2000-2010. Health policy. 2012;106(3):21124.

107. Moe-Byrne T, Chambers D, Harden $\mathrm{M}$ et al. Behaviour change interventions to promote prescribing of generic drugs: a rapid evidence synthesis and systematic review. BMJ open. 2014;4(5):e004623.

108. Godman B, Shrank W, Andersen M et al. Comparing policies to enhance prescribing efficiency in Europe through increasing generic utilization: changes seen and global implications. Expert review of pharmacoeconomics \& outcomes research. 2010;10(6):707-22.

118.

109. Fraeyman J, Van Hal G, Godman B et al. The potential influence of various initiatives to improve rational prescribing for proton pump inhibitors and statins in Belgium. Expert review of pharmacoeconomics \& outcomes research. 2013;13(1):141-51.

110. Moon JC, Godman B, Petzold M et al. Different initiatives across Europe to enhance losartan utilization post generics: impact and implications. Frontiers in pharmacology. 2014;5:219.

111. Voncina L, Strizrep T, Godman B et al. Influence of demand-side measures to enhance renin-angiotensin prescribing efficiency in Europe: implications for the future. Expert review of pharmacoeconomics \& outcomes research. 2011;11(4):469-79.
112. Godman B, Persson M, Miranda J et al. Changes in the utilization of venlafaxine after the introduction of generics in Sweden. Applied health economics and health policy. 2013;11(4):383-93.

113. Godman B, Bucsics A, Burkhardt T et al. Potential to enhance the prescribing of generic drugs in patients with mental health problems in austria; implications for the future. Frontiers in pharmacology. 2012;3:198.

114. Dylst P, Vulto A, Simoens S. Analysis of European policy towards generic medicines. GaBI Journal. 2014;3(1):34-5.

115. Simoens S. International comparison of generic medicine prices. Current medical researchandopinion. 2007;23(11):2647-54.

116. Godman B, Wettermark B, Bishop I et al. European payer initiatives to reduce prescribing costs through use of generics. GaBIJournal 2012;1(1):22-7.

117. Dylst P, Simoens S. Does the market share of generic medicines influence the price level?: a European analysis. PharmacoEconomics. 2011;29(10):875-82.

118. Hassali MA, Thambyappa J, Saleem F, ul Haq N, Aljadhey $\mathrm{H}$ et al. Generic Substitution in Malaysia: Recommendations from a Systematic Review. Journal of Applied Pharmaceutical Science 2012;2(8):159-64.

119. Godman B, Bennie $M$, Baumgärtel $\mathrm{C}$ et al. Essential to increase the use of generics in Europe to maintain comprehensive healthcare? Farmeconomia: Health Economics and Therapeutic Pathways 2012;13 (Suppl3):5-20.

120. Wettermark B, Godman B, Jacobsson B et al. Soft regulations in pharmaceutical policy making: an overview of current approaches and their consequences. Applied health economics and health policy. 2009;7(3):137-47.

121. Gustafsson LL, Wettermark B, Godman B et al. The 'wise list'- a comprehensive concept to select, communicate and achieve adherence to recommendations of essential drugs in 
Initiatives to increase the prescribing of low cost generics; the case of Scotland in the international context

ambulatory care in Stockholm. Basic \& clinical pharmacology \& toxicology. 2011;108(4):224-33.

122. Markovic-Pekovic V, Skrbic R, Godman B et al. Ongoing initiatives in the Republic of Srpska to enhance prescribing efficiency: influence and future directions. Expert review of pharmacoeconomics \& outcomes research. 2012;12(5):661-71.

123. Godman B, Wettermark B, van Woerkom $\mathrm{M}$ et al. Multiple policies to enhance prescribing efficiency for established medicines in Europe with a particular focus on demand-side measures: findings and future implications. Frontiers in Pharmacology Focused Review 2014;5 (Article 106):1-9.

124. Wettermark B, Godman B, Neovius $M$ et al. Initial effects of a reimbursement restriction to improve the cost-effectiveness of antihypertensive treatment. Health policy 2010;94(3):221- 9.

125. Garuoliene K, Godman B, Gulbinovic J et al. European countries with small populations can obtain low prices for drugs: Lithuania as a case history. Expert review of pharmacoeconomics \& outcomes research. 2011;11(3):343-9.

126. Costa J de O, Almeida-Brasil CC, Godman B al. Implementation of clinical guidelines in Brazil: Should academic detailing be used? JPHS 2016;7:105-15.

127. Wettermark B, Pehrsson A, JuhaszHaverinen $M$ et al. Financial incentives linked to self-assessment of prescribing patterns: a new approach for quality improvement of drug prescribing in primary care. Quality in primary care. 2009;17(3):179-89.

128. Godman B, Wettermark B, Miranda $\mathbf{J}$ et al. Influence of multiple initiatives in Sweden to enhance ARB prescribing efficiency following generic losartan; findings and implications for other countries. International journal of clinical practice. 2013;67(9):853-62.
129. Martin A, Godman B, Miranda J et al. Measures to improve angiotensin receptor blocker prescribing efficiency in the UK: findings and implications. Journal of comparative effectiveness research. 2014;3(1):41-51.

130. Abuelkhair M, Abdu S, Godman B et al. Imperative to consider multiple initiatives to maximize prescribing efficiency from generic availability: case history from Abu Dhabi. Expert review of pharmacoeconomics \& outcomes research. 2012;12(1):115-24.

131. Simoens S, De Bruyn K, Miranda J et al. Measures to enhance ARB prescribing efficiency in Belgium following generic losartan: impact and implications for the future. Journal of Pharmaceutical Health Services Research 2013;4:173-81.

132. Bennie M, Godman B, Bishop I et al. Multiple initiatives continue to enhance the prescribing efficiency for the proton pump inhibitors and statins in Scotland. Expert review of pharmacoeconomics \& outcomes research. 2012;12(1):125-30.

133. WHO Collaborating Centre of Drug Statistics Methodology. Guidelines for ATC classification and DDD assignment 2015.

Available at URL:

http://www.whocc.no/filearchive/publicatio ns/2015 guidelines.pdf.

134. (WHO) WHO. Introduction to Drug Utilisation Research. WHO International Working Group for Drug Statistics Methodology, WHO Collaborating Centre for Drug Statistics Methodology, WHO Collaborating Centre for Drug Utilization Research and Clinical Pharmacological Services. ISBN 924156234 X (NLM classification: WB 330). Available at URL: http://www.who.int/medicines/areas/quality _safety/safety_efficacy/Drug\%20utilization \%20research.pdf2003.

135. Godman B, Shrank W, Wettermark $B$ et al. Use of Generics-A Critical Cost Containment Measure for All Healthcare Professionals in Europe? Pharmaceuticals (Basel, Switzerland). 2010;3(8):2470-94. 
Initiatives to increase the prescribing of low cost generics; the case of Scotland in the international context

136. Sermet C, Andrieu V, Godman B et al. Ongoing pharmaceutical reforms in France: implications for key stakeholder groups. Applied health economics and healthpolicy. 2010;8(1):7-24.

137. Dylst P, Vulto A, Simoens S. Analysis of French generic medicines retail market: why the use of generic medicines is limited. Expert review of pharmacoeconomics \& outcomes research. 2014;14(6):795-803.

138. Godman B, Sakshaug S, Berg C et al. Combination of prescribing restrictions and policies to engineer low prices to reduce reimbursement costs. Expert review of pharmacoeconomics \& outcomes research. 2011;11(1):121-9.

139. Brkičić LS, Godman B, Bogut $\mathrm{M}$ et al. Pharmaceutical pricing in Croatia: a comparison of ordinances in 2013 versus 2009 and their potential savings to provide future guidance. GaBI Journal. 2015;4(2):79-89.

140. Andersson KA, Petzold MG, Allebeck $\mathrm{P}$ et al. Influence of mandatory generic substitution on pharmaceutical sales patterns: a national study over five years. BMC health services research. 2008;8:50.

141. Godman B, Bucsics A, Burkhardt T et al. Insight into recent reforms and initiatives in Austria: implications for key stakeholders. Expert review of pharmacoeconomics \& outcomes research. 2008;8(4):357-71.

142. Bucsics A, Godman B, Burkhardt T et al. Influence of lifting prescribing restrictions for losartan on subsequent sartan utilization patterns in Austria: implications for other countries. Expert review of pharmacoeconomics \& outcomes research. 2012;12(6):809-19.

143. Ustawa $\mathrm{z}$ dnia 12 maja 2011 r. o refundacji leków, środków spożywczych specjalnego przeznaczenia żywieniowego oraz wyrobów medycznych (Act of 12-th of May 2011 on reimbursement of medicines, food products for special dietary use and medical devices) (Dz.U. $2011 \mathrm{nr} 122$ poz. 696 z późn. zm.).

144. Obwieszczenie $\mathrm{z}$ dnia 28 grudnia $\mathrm{w}$ sprawie wykazu refundowanych lekow, srodkow spożywczych specjalnego przeznaczenia żywieniowego oraz wyrobow medycznych (Announcement of 28 December 2016 on list of reimbursed medicines, food products for special dietary use and medical devices). Available at URL:

http://www.bip.mz.gov.pl/legislacja/aktyprawne-1/obwieszczenie-z-dnia-28-grudnia2016-r-w-sprawie-wykazu-refundowanychlekow-srodkow-spozywczych-specjalnegoprzeznaczenia-zywieniowego-orazwyrobow-medycznych-na-1-stycznia-2017rl.

145. McKee M, Stuckler D, MartinMoreno JM. Protecting health in hard times. BMJ. 2010;341:c5308.

146. Thai LP, Moss JR, Godman B, Vitry AI. Cost driver analysis of statin expenditure on Australia's Pharmaceutical Benefits Scheme. Expert review of pharmacoeconomics \& outcomes research. 2016;16(3):419-33.

147. Mansfield SJ. Generic drug prices and policy in Australia: room for improvement? a comparative analysis with England. Australian health review. 2014;38(1):6-15.

148. Ezenduka C, Ubochi V, Ogbonna B. The Utilization Pattern and Costs Analysis of Psychotropic Drugs at a Neuropsychiatric Hospital in Nigeria. British Journal of Pharmaceutical Research. 2014;4(3):325-37. 149. Godman B, Ezenduka C, Bennie M et al. BARRIERS TO THE OPTIMAL USE OF PHARMACOTHERAPY TO MANAGE DEPRESSION AND SCHIZOPHRENIA: IMPLICATIONS AND FUTURE DIRECTION. Basic \& clinical pharmacology \& toxicology. 2014;115 (Suppl 1):180.

150. Godman B, Bishop I, Campbell SM et al. Quality and efficiency of statin prescribing across countries with a special 
Initiatives to increase the prescribing of low cost generics; the case of Scotland in the international context

focus on South Africa; findings and future implications. Expert review of pharmacoeconomics \& outcomes research. 2015;15(2):323-30.

151. Novartis. Kenya first country to launch 'Novartis Access', expanding affordable treatment options against chronic diseases. Available at URL: https://www.novartis.com/news/mediareleases/kenya-first-country-launchnovartis-access-expanding-affordabletreatment.

152. Bennie M, Bishop I, Godman B et al. Are prescribing initiatives readily transferable across classes: the case of generic losartan in Scotland? Quality in primarycare. 2013;21(1):7-15.

153. Bennie M, Bishop I, Godman B et al. Are specific initiatives required to enhance prescribing of generic atypical antipsychotics in Scotland?: International implications. International journal of clinical practice. 2013;67(2):170-80.

154. Barton S. Using clinical evidence. BMJ. 2001;322(7285):503-4.

155. Bero LA, Grilli R, Grimshaw JM et al. Closing the gap between research and practice: an overview of systematic reviews of interventions to promote the implementation of research findings. The Cochrane Effective Practice and Organization of Care Review Group. BMJ. 1998;317(7156):465-8.

156. McGinn D, Godman B, Lonsdale J et al. Initiatives to enhance the quality and efficiency of statin and PPI prescribing in the UK: impact and implications. Expert review of pharmacoeconomics \& outcomes research. 2010;10(1):73-85.

157. NHS. Prescriptions Dispensed in the Community. England 2005-2015. Available cia URL:

http://content.digital.nhs.uk/catalogue/PUB2 0664/pres-disp-com-eng-2005-15-rep.pdf.

158. Baumgartel C. Myths, questions, facts about generic drugs in the EU. GaBI Journal. 2012;1(1):34-8.
159. Andersson K, Sonesson C, Petzold $\mathrm{M}$ et al. What are the obstacles to generic substitution? An assessment of the behaviour of prescribers, patients and pharmacies during the first year of generic substitution in Sweden. Pharmacoepidemiology and drug safety. 2005;14(5):341-8.

160. Andersson K, Jorgensen T, Carlsten A. Physicians' opinions and experiences of the Pharmaceutical Benefits Reform. Scandinavian journal of public health. 2006;34(6):654-9.

161. Godman B, Persson M, Miranda J et al. Can authorities take advantage of the availability of generic atypical antipsychotic drugs:? Findings from Sweden and potential implications. Journal of Pharmaceutical Health Services Research 2013;4:139-50.

162. Olsson E, Kalvemark Sporrong S. Pharmacists' experiences and attitudes regarding generic drugs and generic substitution: two sides of the coin. The International journal of pharmacy practice. 2012;20(6):377-83.

163. MHRA. Antiepileptic drugs: new advice on switching between different manufacturers ${ }^{\text {ee }}$ products for a particular drug. Available at URL: http://www.mhra.gov.uk/Safetyinformation/ DrugSafetyUpdate/CON3367162013. 164. Ofori-Asenso R. A closer look at the World Health Organization's prescribing indicators. Journal of pharmacology \& pharmacotherapeutics. 2016;7(1):51-4.

165. Ofori-Asenso R, Brhlikova P, Pollock AM. Prescribing indicators at primary health care centers within the WHO African region: a systematic analysis (19952015). BMC public health. 2016;16:724.

166. Hayden C. A Generic Solution? Pharmaceuticals and the Politics of the Similarin Mexico. Current Anthropology.48(4):475-95.

167. IMS. Institute for Healthcare Informatics. Global Medicines Use in 2020. Outlook and Implications. Nov 2015. Available at URL: 
Initiatives to increase the prescribing of low cost generics; the case of Scotland in the international context

http://www.imshealth.com/en/thought-

leadership/quintilesims-

institute/reports/global-medicines-use-in2020.

168. Nishijima M. Os preços dos medicamentos de referência após a entrada dos medicamentos genéricos no mercado farmacêutico brasileiro. Rev Bras Econ. 2008;62(2):189-206.

169. Vieira FS, Zucchi P. Diferenças de preços entre medicamentos genéricos e de referência no Brasil (Price differences between generic and innovator medicinesin Brazil). Rev Saúde Pública 40(3):444-9.

170. Truter I. Impact of Generic Substitution On the Prescribing of Meprobamate-Containing Combination Analgesics In South Africa. Value in health. 2014;17(7):A526.

171. Truter I. Prescribing of meprobamatecontaining combination analgesics in South Africa. South African Family Practice 2016;58(6):207-12.

172. Zeng W, Gustafsson LL, Bennie M

et al. Review of ongoing initiatives to improve prescribing efficiency in China; angiotensin receptor blockers as a case history. Expert review of pharmacoeconomics \& outcomes research. 2015;15(1):157-69.

173. Zeng W. A price and use comparison of generic versus originator cardiovascular medicines: a hospital study in Chongqing, China. BMC health services research. 2013;13(1):390.

174. Zeng W, Zhen J, Feng $M$ et al. Analysis of the influence of recent reforms in China: cardiovascular and cerebrovascular medicines as a case history to provide future direction. Journal of comparative effectiveness research. 2014;3(4):371-86.

175. Zeng W XH, Godman B, Finlayson $\mathrm{AE}$ et al. Ongoing initiatives to improve prescribing efficiency in China; statins as a case history GaBI Journal. 2014;3(3):12232.
176. Li Y, Xu J, Wang F, Wang B et al. Overprescribing in China, driven by financial incentives, results in very high use of antibiotics, injections, and corticosteroids. Health affairs. 2012;31(5):1075-82.

177. Reynolds L, McKee M. Serve the people or close the sale? Profit-driven overuse of injections and infusions in China's market-based healthcare system. The International journal of health planning and management. 2011;26(4):449-70.

178. Zeng W, Finlayson AE, Shankar S et al. Prescribing efficiency of proton pump inhibitors in China: influence and future directions. BMC health services research. 2015;15(1):11.

179. Li M, Cai J, Zhang P, Fei C, Xu F. Drug Brand Response and Its Impact on Compliance and Efficacy in Depression Patients. Frontiers in pharmacology. 2017;7(540).

180. Moon JC, Flett AS, Godman BB et al. Getting better value from the NHS drug budget. BMJ. 2010;341:c6449.

181. Usher-Smith J, Ramsbottom T, Pearmain $\mathrm{H}$ et al. Evaluation of the clinical outcomes of switching patients from atorvastatin to simvastatin and losartan to candesartan in a primary care setting: 2 years on. International journal of clinical practice. 2008;62(3):480-4.

182. Corrao G, Soranna D, La Vecchia C et al. Medication persistence and the use of generic and brand-name blood pressurelowering agents. Journal of hypertension. 2014;32(5):1146-53; discussion 53.

183. Martikainen JE, Saastamoinen LK, Korhonen MJ et al. Impact of restricted reimbursement on the use of statins in Finland: a register-based study. Medical care. 2010;48(9):761-6.

184. Godman B, Malstrom R, Bennie M et al. Prescribing restrictions - a necessary strategy among some European countries to enhance future prescribing efficiency?'. Reviews in Health Care. 2012;3(1):5-16. 
Initiatives to increase the prescribing of low cost generics; the case of Scotland in the international context

185. Godman B, Schwabe U, Selke G et al. Update of recent reforms in Germany to enhance the quality and efficiency of prescribing of proton pump inhibitors and lipid-lowering drugs. PharmacoEconomics. 2009;27(5):435-8.

186. Moon JC, Bogle RG. Switching statins. BMJ. 2006;332(7554):1344-5.

187. Gellad WF, Donohue JM, Zhao X et al. Brand-name prescription drug use among Veterans Affairs and Medicare Part D patients with diabetes: a national cohort comparison. Annals of internal medicine. 2013;159(2):105-14.

188. Wu H-Y, Huang J-W, Lin H-J et al. Comparative effectiveness of reninangiotensin system blockers and other antihypertensive drugs in patients with diabetes: systematic review and bayesian networkmeta-analysis. BMJ.2013;347.

189. Godman B, Bucsics A, Burkhardt T et al. Initiatives to enhance reninangiotensin prescribing efficiency in Austria: impact and implications for other countries. Expert review of pharmacoeconomics \& outcomes research. 2010;10(2):199-207.

190. Kalaba M, Godman B, Vuksanovic A et al. Possible ways to enhance reninangiotensin prescribing efficiency: Republic of Serbia as a case history? Journal of comparative effectiveness research. 2012;1(6):539-49.

191. Hesse U, Godman B, Petzold M et al. Impact of delisting ARBs, apart from losartan, on ARB utilisation patterns in Denmark: implications for other countries. Applied health economics and health policy. 2013;11(6):677-85.

192. Weng TC, Yang YH, Lin SJ, Tai SH. A systematic review and meta-analysis on the therapeutic equivalence of statins. Journal of clinical pharmacy and therapeutics. 2010;35(2):139-51.

193. Godman B, Burkhardt T, Bucsics A et al. Impact of recent reforms in Austria on utilization and expenditure of PPIs and lipid-lowering drugs: implications for the future. Expert review of pharmacoeconomics \& outcomes research. 2009;9(5):475-84.

194. Parks J, Radke A, Parker G et al. Principles of antipsychotic prescribing for policy makers, circa 2008. Translating knowledge to promote individualized treatment. Schizophrenia bulletin. 2009;35(5):931-6.

195. Leucht S, Cipriani A, Spineli L etal. Comparative efficacy and tolerability of 15 antipsychotic drugs in schizophrenia: a multiple-treatments meta-analysis. Lancet. 2013;382(9896):951-62.

196. Godman B, Petzold M, Bennett K et al. Can authorities appreciably enhance the prescribing of oral generic risperidone to conserve resources?: Findings from across Europe and their implications. BMC medicine. 2014;12(1):98.

197. Godman B, De Bruyn K, Miranda J et al. Generic atypical antipsychotic drugs in Belgium: their influence and implications. Journal of comparative effectiveness research. 2013;2(6):551-61.

198. Pettersson B, Hoffmann M, Wandell $P$ et al Utilization and costs of lipid modifying therapies following health technology assessment for the new reimbursement scheme in Sweden. Health policy. 2012;104(1):84-91.

199. PrescQIPP. Switching rosuvastatin to atorvastatin. Available at URL: https://www.prescqipp.info/rosuvastatin/sen d/132-rosuvastatin/1692-bulletin-81-

rosuvastatin.

200. Audit Scotland. Prescribing in general practice in Scotland. Available at URL http://www.auditscotland.gov.uk/docs/health/2013/nr 13012 4_gp_prescribing.pdf.

201. Lothian Prescribing Bulletin 77. Available at URL: http://www.ljf.scot.nhs.uk/PrescribingBullet ins/Prescribing\%20Bulletins/Lothian\%20Pr escribing\%20Bulletin\%20Issue\%2077\%20J anuary $\% 202016 \% 20$ FINAL.pdf. 
Initiatives to increase the prescribing of low cost generics; the case of Scotland in the international context

202. NHS Highland Formulary. Available at URL:

http://www.nhshighland.scot.nhs.uk/publica tions/documents/guidelines/formulary/highl and\%20formulary.pdf.

203. NHS Greater Glasgow and Clyde Medicines Update Primary Care. Available at URL:

http://ggcprescribing.org.uk/blog/medicinesupdate-primary-care-supplement-no2-april/.
204. Bogaert P, Bochenek T, Prokop A et al. A Qualitative Approach to a Better Understanding of the Problems Underlying Drug Shortages, as Viewed from Belgian, French and the European Union's Perspectives. PloS one. 2015;10(5):e0125691.

205. Kwon HY, Hong JM, Godman B, Yang BM. Price cuts and drug spending in South Korea: the case of antihyperlipidemic agents. Healthpolicy. 2013;112(3):217-26. 